DOI: $10.1002 / 201804138$

Article type: Full Paper

\title{
Silica Nanofibrous Membranes for the Separation of Heterogeneous Azeotropes
}

Eva Loccufier, Jozefien Geltmeyer, Lode Daelemans, Dagmar R. D’hooge, Klaartje De Buysser, Karen De Clerck*

E. Loccufier, Dr. J. Geltmeyer, Dr. L. Daelemans, Prof. D.R. D’hooge, Prof. K. De Clerck Department of Materials, Textiles and Chemical Engineering (MaTCh), Faculty of Engineering and Architecture, Ghent University, Technologiepark 907, 9052 Ghent, Belgium E-mail: Karen.DeClerck@ugent.be

Prof. K. De Buysser

Sol-gel Centre for Research on Inorganic Powders and Thin Films Synthesis (SCRiPTS), Department of Chemistry, Faculty of Sciences, Ghent University, Krijgslaan 281 S3, 9000 Ghent, Belgium

Keywords: electrospun nanofibrous membranes, silica, wettability switch, heterogeneous azeotrope separation

\section{Abstract}

Nanofibrous materials produced through electrospinning are characterized by a high porosity, large specific surface area and high pore interconnectivity and therefore, show potential for e.g. separation and filtration. The development of more inert nanofibers with higher thermal and chemical resistance extends the application field to high-end purification. Silica nanofibrous membranes produced by direct electrospinning of a sol-gel solution without a sacrificing carrier, starting from tetraethoxysilane (TEOS), meet these challenging requirements. After electrospinning the membrane is highly hydrophobic. Storage under dry conditions preserves this property. Oppositely, a superhydrophilic membrane is obtained by storage under high humidity (month scale). This switch is caused by the reaction of ethoxy groups, present due to incomplete hydrolysis of the precursor, with moisture in the air, resulting in an increased amount of silanol groups. This transition can be accelerated to hour scale by applying a heat treatment, with the additional increase in cross-linking density for temperatures above $400^{\circ} \mathrm{C}$, enabling applications that make use of hydrophobic and hydrophilic membranes by tuning the functionalization. It is showcased that upon designing 


\section{WILEY-VCH}

the water repellent or absorbing nature of the silica material, fast gravity driven membrane separation of heterogeneous azeotropes can be achieved.

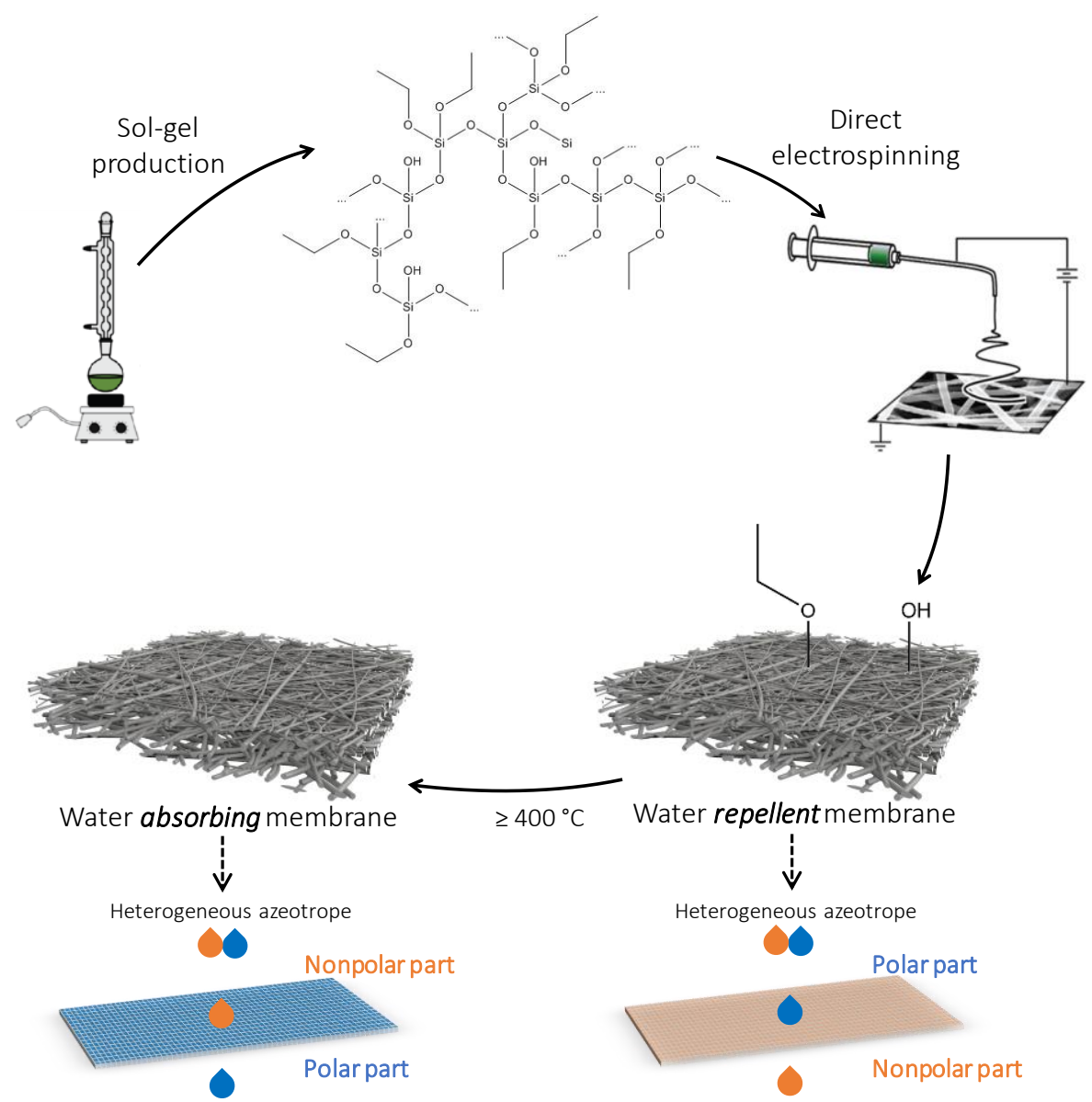

Figure 1. Silica nanofibers produced via direct electrospinning of a TEOS-based sol-gel solution create a water repellent membrane. An efficient switch to a water absorbing membrane is achieved by a heat treatment at $400^{\circ} \mathrm{C}$ or higher. In this way, gravity driven separation of heterogeneous azeotropes can be achieved via two routes.

\section{Introduction}

The wettability of a membrane structure has a strong influence on its performance and application field. ${ }^{[1-6]}$ A (super)hydrophobic membrane, which is characterized by a high water contact angle and low contact angle hysteresis, has potential applications in for instance microfluidics, as water-repellent textile, in membrane distillation units, and in oil-water separation. ${ }^{[7-10]}$ On the other hand, a (super)hydrophilic membrane is beneficial for a whole range of other applications in which a water-rich stream has to pass through the membrane structure with a low pressure drop and high flux, such as particle-size based separation or photo- 


\section{WILEY-VCH}

catalytic degradation of organic micro-pollutants. ${ }^{[11,12]}$ This behavior is dependent on a subtle balance between the surface chemistry and the morphology of the membrane structure, such as pore size, pore size distribution, and surface roughness, and can be tuned by various functionalization strategies. $^{[7,13,14]}$

A promising route towards membranes with a high flux and hydrophobic or hydrophilic properties is electrospinning. ${ }^{[15-18]}$ Electrospinning is a technique by which a viscous polymer solution is drawn into nanofibers in the presence of an electric field. ${ }^{[19-21]}$ Today electrospun nanofibrous structures are of high interest for membrane applications, due to their high surface to volume ratio, high porosity, and high interconnectivity of the pores, leading to the desired high permeation flux and low pressure drop over the membrane. ${ }^{[20,22,23]}$ In addition, these nanofibrous membranes consist of continuous entangled fibers, creating a three-dimensional porous network structure, making them ideal materials for separation and absorption applications. ${ }^{[24]}$

To increase the chemical and thermal resistance of nanofibrous structures, ceramic variants are being developed, which widens the application potential towards harsh environments, e.g. industrial acidic waste streams. ${ }^{[21]}$ Recently, our group successfully produced ceramic silica nanofibers without the need of a sacrificing polymer. ${ }^{[25,26]}$ In contrast to other work, in which a well-spinnable organic polymer is mixed with a metal oxide precursors to facilitate the electrospinning process, ${ }^{[15,21,27-29]}$ direct electrospinning of a sol-gel solution of a tetraethyl orthosilicate (TEOS) precursor eliminates the need for a post-production removal of the organic polymer component. ${ }^{[30-32]}$ This results in dense silica nanofibers with superior mechanical properties, without a rough and uneven surface of the fibers. ${ }^{[33,34]}$ In addition and even more important, it offers the benefits of a simple, more tunable material design.

The present work focuses on the wettability of these directly spun amorphous silica nanofibrous membranes. Special attention is given to facile routes to tune the wettability of the membranes from water repellent to highly water absorbing membranes through treatment at room and 


\section{WILEY-VCH}

elevated temperatures. This allows for a large range of application targets. Direct electrospinning of the TEOS sol-gel system has a high potential for the desired wettability properties as the surface chemical properties can be controlled after synthesis.

Proof-of-concept of the designed material is done by investigating the separation of heterogeneous azeotropes, as conceptually depicted in Figure 1. Azeotropes, also called "constant-boiling mixtures", are liquid mixtures with the same vapor phase and liquid phase composition at the azeotropic temperature and, hence, separation with conventional distillation is impossible, urging the need for other separation techniques. ${ }^{[35]}$

Focus is on the separation of one type of azeotropes, namely heterogeneous binary azeotropic mixtures, into the two pure phases (e.g. toluene - water, methanol - hexane, and ethanol heptane). This separation, and more in general that of two immiscible liquids into two separated phases, is an important assignment in various sectors, such as (petro-)chemical, biotechnological, pharmaceutical as well as in the food industry. ${ }^{[36,37]}$ It is illustrated how (super)hydrophobic or -hydrophilic electrospun membranes allow separation in a single-unit operation by using the difference in capillary forces acting on the two phases with fast gravity driven separation (bottom Figure 1). ${ }^{[38-39]}$ In this way, energy intensive methods such as heteroazeotropic distillation, extraction, centrifugal separation or decantation can be avoided. ${ }^{[35-37,41-42]}$

\section{Results and discussion}

\subsection{Evolution of hydrophilicity at room temperature}

Silica nanofibrous membranes were produced via electrospinning of an acid-catalyzed sol-gel solution, with its building blocks derived from TEOS. An overview of the key chemical reactions is given in Figure 2, with in a first phase hydrolysis converting part of the ethoxy groups of TEOS in hydroxyl groups (silanols) and in a second phase condensation of the latter groups, resulting in the formation of silicon-oxygen-silicon bonds. Eventually, this leads in a third phase to a loosely cross-linked, hence, electrospinnable sol-gel solution. 


\section{WILEY-VCH}

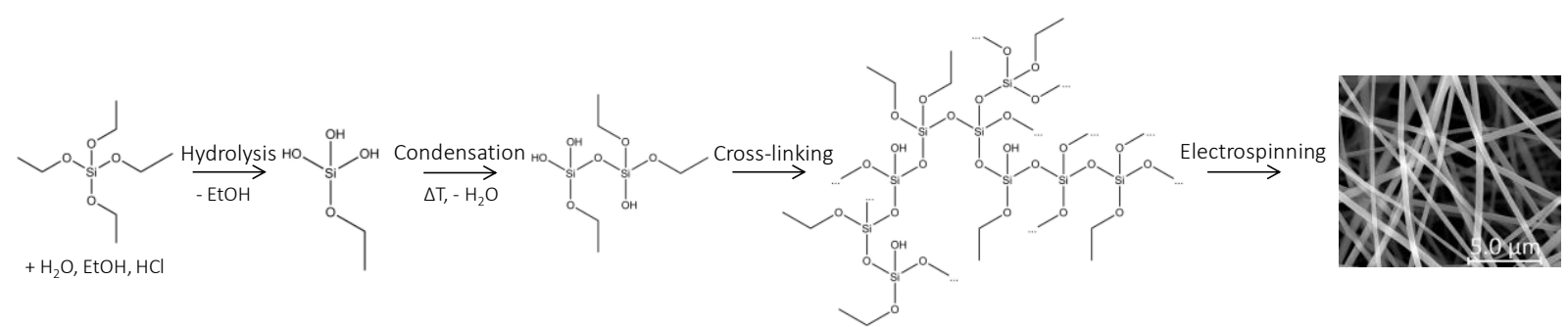

Figure 2. Principle of the production of silica nanofibrous membranes via electrospinning. Due to hydrolysis and condensation of a mixture containing TEOS, ethanol (EtOH), water, and $\mathrm{HCl}$ (molar ratios 1:2:2:0.01), a loosely cross-linked 3D electrospinnable network is obtained.

After electrospinning the membrane is highly hydrophobic, as confirmed by a stable high $\left(>140^{\circ}\right.$ ) contact angle (Figure 3). Over time, when stored in humid atmosphere, the membrane switches to superhydrophilic (water contact angle $<5^{\circ}$ ). When stored at room temperature (RT, $20^{\circ} \mathrm{C}$ ) and $65 \%$ relative humidity $(\mathrm{RH})$, the hydrophobic/hydrophilic switch is observed after 4 months (right region of Figure 3). In case of a $\mathrm{RH}$ of $90 \%$, the membrane is superhydrophilic within 21 days. ${ }^{[44]}$ The lower the relative humidity, the longer the hydrophobic nature lasts. Thus, the hydrophobic/hydrophilic switch can be controlled by the storage conditions, enabling applications that make use of hydrophobic or hydrophilic membranes.

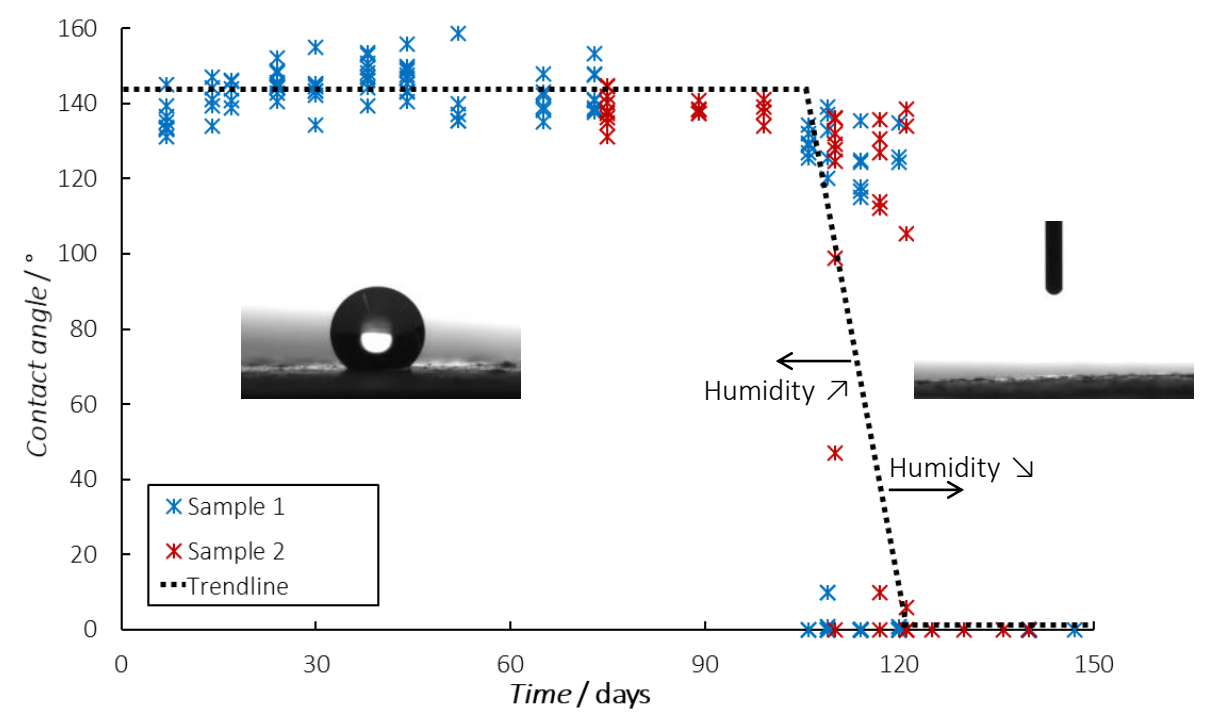

Figure 3. Evolution of the water contact angle of two silica nanofibrous membranes over time at $20^{\circ} \mathrm{C}$ and $65 \% \mathrm{RH}$. The contact angle is stable for over ca. 100 days, resulting in a hydrophobic, almost superhydrophobic $\left(>150^{\circ}{ }^{[45]}\right)$ structure. After ca. 100 days, there is a switch to a superhydrophilic $\left(<5^{\circ}\right)$ membrane, which can be explained by further hydrolysis combined with the capillary effect of the nanofibrous porous structure (cf. discussion of Figure 4, 5 and 7). This transition can be accelerated by increasing $\mathrm{RH}$, or delayed by lowering the $\mathrm{RH} .{ }^{[44]}$ 


\section{WILEY-VCH}

In this work, starting from the principles outlined by Zhuravlev, a thorough investigation of the surface chemistry of the amorphous silica nanofibrous membrane is therefore applied in order to understand and tune the wettability. ${ }^{[46-48]}$ In comparison to amorphous silica films and powders, the capillary effect due to the large pores ( $\mu \mathrm{m}$ range) and the high porosity of the nanofibrous membrane has a significant influence on the wettability of the membrane structure. In addition, the roughness of the surface will be different, significantly influencing the wettability of a structure. ${ }^{[48-50]}$

The chemical change leading to the hydrophobic/hydrophilic switch is studied via Attenuated Total Reflectance-Fourier Transform Infrared (ATR-FTIR), Figure 4. A complete assignment of all peaks is given in Table $\mathbf{S 1}$ in the Supporting Information. Figure 4a shows the evolution with time of the measured ATR-FTIR spectra of a sample maintained at room temperature and $65 \% \mathrm{RH}$ and Figure $4 \mathrm{~b}$ the corresponding change in surface area of several characteristic peaks (complete overview see Table S2, Supporting Information). The indicated peaks change significantly over time and are all related to hydrophobic ethoxy groups $\left(-\mathrm{OCH}_{2} \mathrm{CH}_{3}\right)$ and hydrophilic silanol (Si-OH) vibrations. The peaks related to ethoxy groups gradually decrease in intensity, leading to complete removal of the hydrophobic groups over time. There is a decrease in -OH out of plane vibrations, combined with a shift, consistent with an evolution to less and different $-\mathrm{OH}$ bonds in the material, indicative of the evolution of the amount of absorbed water and silanol groups. 

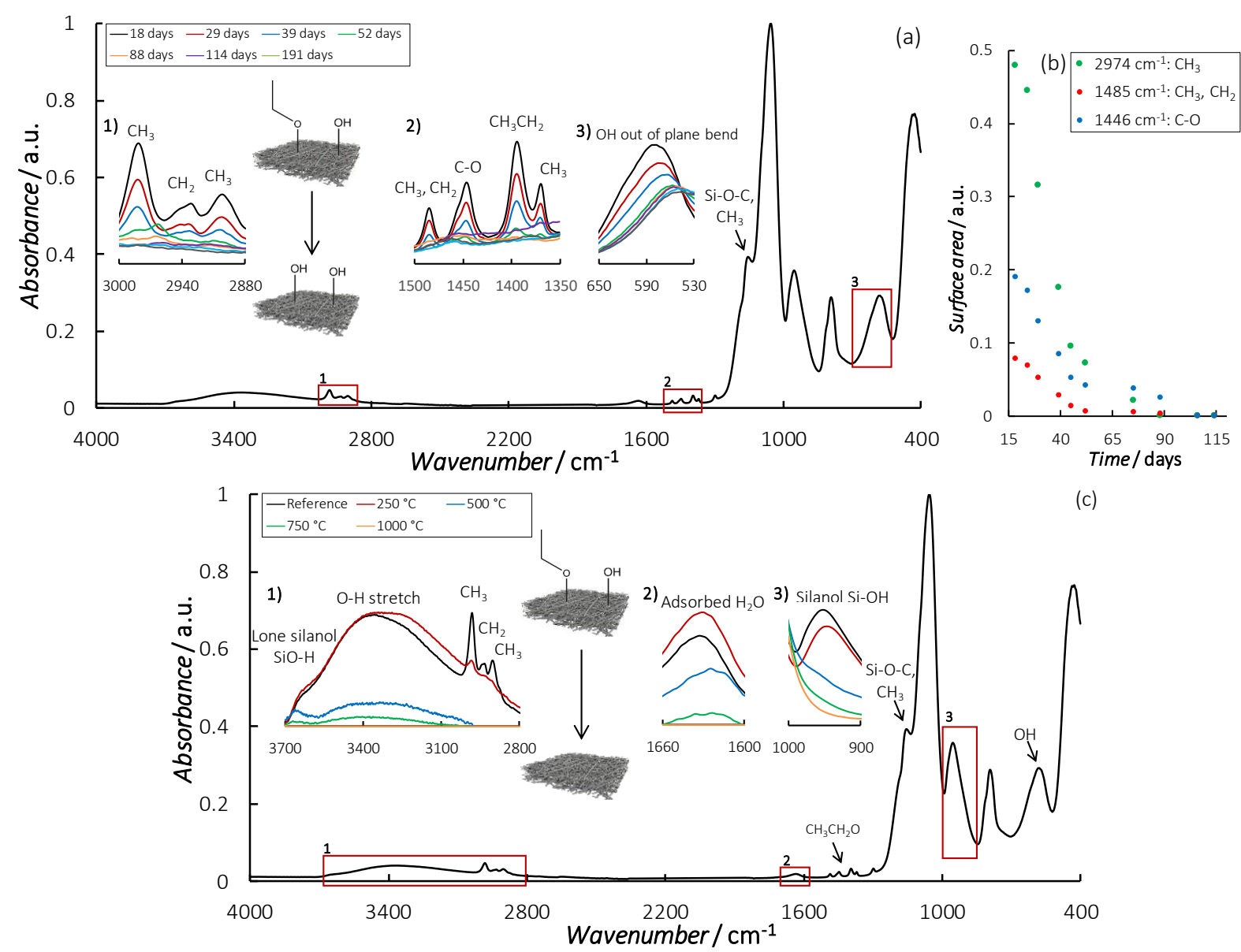

Figure 4. (a) ATR-FTIR spectra indicating the evolution of the molecular structure of silica nanofibers over time at room temperature and $65 \% \mathrm{RH}$. Due to incomplete hydrolysis of the TEOS precursor during sol-gel production, ethoxy groups $\left(-\mathrm{OCH}_{2} \mathrm{CH}_{3}\right)$ are present in the fibrous structure after electrospinning (Figure 2, right). Over time, these groups are gradually converted in polar groups. (b) Evolution of surface area underneath characteristic peaks of the normalized ATR-FTIR spectra over time (complete overview Table S2, Supporting Information). The surface areas gradually decrease until no peaks related to $-\mathrm{OCH}_{2} \mathrm{CH}_{3}$ vibrations and stretches are observed. (c) ATR-FTIR spectra of silica nanofibers after various heat treatments for $3 \mathrm{~h}$. These spectra indicate a gradual change in chemical nature due to reaction of remaining ethoxy and silanols accelerated at a higher treatment temperature. Peaks marked with an arrow show a similar trend.

The spectra of all samples were normalized based on the height of the largest peak, i.e. the peak at $1076 \mathrm{~cm}^{-1}$ attributed to $\mathrm{Si}-\mathrm{O}-\mathrm{Si}$ vibrations.

The evolutions in Figure 4 is further confirmed by Thermal Gravimetric Analysis - Mass Spectrometry (TGA-MS) experiments. A hydrophobic silica membrane (left region Figure 3) and a hydrophilic membrane stored at room temperature and $65 \% \mathrm{RH}(>4$ months after production; right region of Figure 3) are compared in Figure 5. The mass loss of a hydrophobic sample is $22 \pm 3 \mathrm{~m} \%$, compared to $11 \pm 3 \mathrm{~m} \%$ for a hydrophilic. A hydrophobic sample shows significant mass spectrometer peaks for $\mathrm{C}_{2} \mathrm{H}_{4}, \mathrm{H}_{2} \mathrm{O}, \mathrm{CO}_{2}, \mathrm{CO}$, and $\mathrm{C}_{2} \mathrm{H}_{2}$, related to the 


\section{WILEY-VCH}

incomplete hydrolysis during sol-gel production and after electrospinning. In contrast, the hydrophilic, long-term stored sample only has significant peaks of $\mathrm{H}_{2} \mathrm{O}$ and $\mathrm{CO}_{2}$, of which both signals are one order of magnitude smaller than the fresh membrane. This indicates a permanent removal of ethoxy groups due to reaction at room temperature with moisture in the air, resulting in a silica nanofibrous membrane with exclusively hydrophilic silanol functionalities. In both cases, all organic species left are removed above $450^{\circ} \mathrm{C}$.
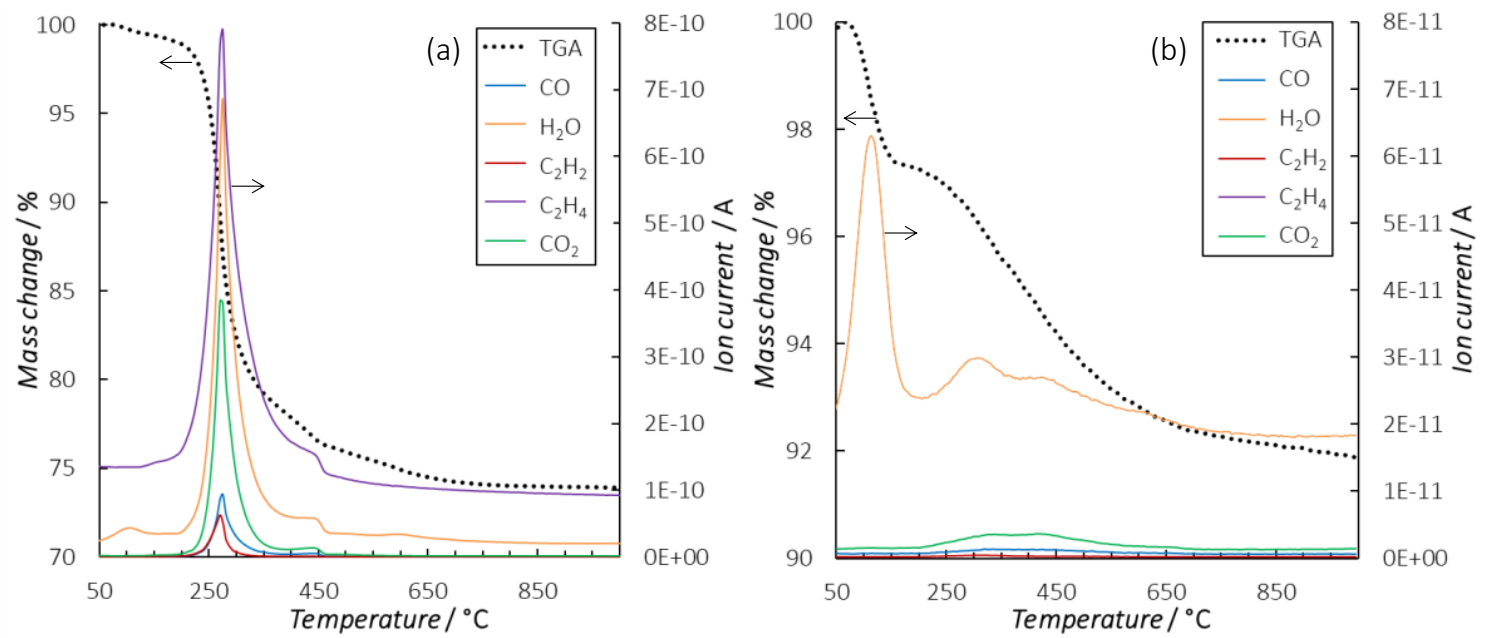

Figure 5. TGA-MS results of silica nanofibers (a) just after electrospinning (hydrophobic; left region of Figure 3) and (b) after 5 months at room temperature and $65 \% \mathrm{RH}$ (superhydrophilic; right region of Figure 3). (a) shows significant release of $\mathrm{C}_{2} \mathrm{H}_{4}, \mathrm{H}_{2} \mathrm{O}, \mathrm{CO}_{2}$, $\mathrm{CO}$ and $\mathrm{C}_{2} \mathrm{H}_{2}$ if heated at $10^{\circ} \mathrm{C} / \mathrm{min}$ up to $1000^{\circ} \mathrm{C}$ under helium atmosphere; in (b), only significant peaks of $\mathrm{H}_{2} \mathrm{O}$ and $\mathrm{CO}_{2}$ are detected. Ethoxy groups present after electrospinning eventually react with moisture in the air, resulting in a permanent transition to a superhydrophilic structure; dotted lines: TGA, colored lines: ion currents measured with MS.

\subsection{Heat-induced wettability switch}

The silica nanofibrous membranes were subjected to external heat to investigate the potential of accelerating the hydrophobic/hydrophilic switch in high humidity environments. ${ }^{[51]}$ As such, use of a superhydrophilic silica nanofibrous membranes for advanced separation applications becomes very straightforward. Scanning Electron Microscopy (SEM) images were recorded to demonstrate that these silica nanofibers are able to resist treatments up to $1300^{\circ} \mathrm{C}$ (Figure $\mathbf{S 1}$, Supporting Information). The membrane remains intact without changes in morphology nor significant loss in fiber diameter (average diameter of fresh silica membrane: $316 \pm 175 \mathrm{~nm}$ ) till $1000^{\circ} \mathrm{C}$. At $1300^{\circ} \mathrm{C}$, the fibers are still intact, but the membrane has shrunken significantly, 
due to partial crystallization of the silica structure to cristobalite (Figure S2, Supporting Information). It is important to note that this high temperature stability is the result of the direct electrospinning of the TEOS sol-gel system, in contrast to the more conventional synthesis with the addition of a carrying organic polymer where highly porous nanofibers with poorer mechanical properties are created. Moreover the good mechanical properties and flexibility of the silica nanofibrous membranes produced by the direct electrospinning of a sol-gel system were demonstrated by determining the recovery from creasing of samples with various treatments, in line with the ISO 2313:1972 standard for textile materials (Figure S3 and Table S3, Supporting Information). A short heat treatment even increases the flexibility and reduces the damage, allowing stand-alone use.

ATR-FTIR spectra after various heat treatments $\left(250,500,750\right.$, and $\left.1000^{\circ} \mathrm{C}\right)$ for 3 hours reveal a similar trend as samples kept in high RH at room temperature with respect to the removal of remaining ethoxy groups (Figure 4c), resulting in a hydrophobic/superhydrophilic wettability switch. For a treatment at $250^{\circ} \mathrm{C}$, a significant decrease of the ethoxy related peaks is noticed, but a higher treatment temperature is required to obtain a complete removal of the hydrophobic ethoxy groups resulting in a switch to a superhydrophilic material. In addition, an evolution of peaks related to silanols and adsorbed water was monitored. At $250{ }^{\circ} \mathrm{C}$, only a slight decrease in silanols and increase of adsorbed water is observed, because of the decrease in water repellent ethoxy groups while the hydrophilic silanols remain. Higher treatment temperatures result in a further decrease in silanols, resulting in a reduction of adsorbed water. This decrease in silanols is assigned to an increase in cross-linking density of the silica nanofibrous structure. This is confirmed by ${ }^{29} \mathrm{Si}$ solid state NMR in Figure S4 in the Supporting Information by measuring the $\mathrm{Q}^{1}-\mathrm{Q}^{4}$ species, where $\mathrm{Q}^{1}$ refers to one $\mathrm{Si}-\mathrm{O}-\mathrm{Si}$ bond, $\mathrm{Q}^{2}$ to two Si-O-Si bonds, etc. By applying a heat treatment at $500^{\circ} \mathrm{C}$ and $1000^{\circ} \mathrm{C}$, there is a significant increase in $\mathrm{Q}^{4}$ species and a decrease in $\mathrm{Q}^{2}$ and $\mathrm{Q}^{3}$ species, and thus a significant increase in cross-linking density due to further condensation of the amorphous silica network. This further condensation is gradual, see 


\section{WILEY-VCH}

Figure S5 in the Supporting Information, where the decrease in silanols is demonstrated for treatments at $400^{\circ} \mathrm{C}$ and $450^{\circ} \mathrm{C}$. The longer the treatment temperature, the more silanols are removed. By increasing the treatment temperature, the removal of silanols is accelerated.

Isothermal TGA experiments illustrate the influence of the applied heating temperature on the mass loss over time (Figure 6a). At $400^{\circ} \mathrm{C}$ or higher, a very fast mass loss of $22 \pm 3 \mathrm{~m} \%$ is measured. Lowering the treatment temperature slows down the chemical process and lowers the mass loss. Hence, a distinction between a heat treatment at lower $\left(<400^{\circ} \mathrm{C}\right)$ and higher temperature $\left(\geq 400^{\circ} \mathrm{C}\right)$ needs to be made. Below $400^{\circ} \mathrm{C}$, complete removal of silanols cannot be achieved, resulting in a lower mass loss. Nevertheless, all heat treatments are able to achieve a superhydrophilic structure (Figure 6b-c), and thus removing the hydrophobic ethyl (ethoxy) groups. The time required to reach the hydrophobic/superhydrophilic membrane switch follows an Arrhenius equation as typical for chemical conversions, explaining the required exponential time scale. 


\section{WILEY-VCH}
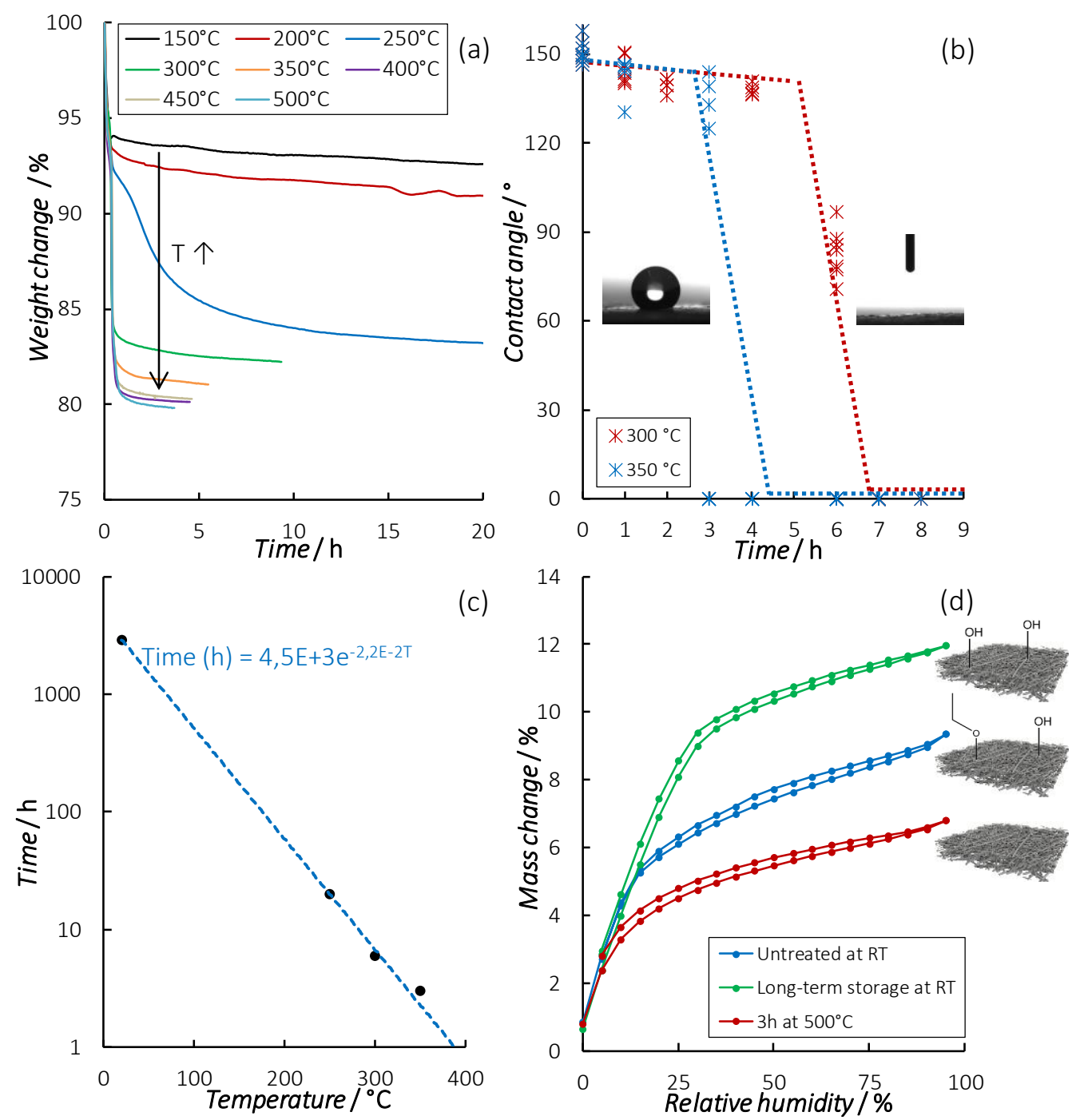

Figure 6. (a) Isothermal TGA measurements of silica nanofibers show a stronger and faster mass loss at higher temperatures. (b) Evolution of the water contact angle upon applying a heat treatment at 300 and $350^{\circ} \mathrm{C}$ for varying time (hour scale), indicating that the membrane switches to a superhydrophilic membrane. (c) Evolution of the heating time required for obtaining a superhydrophilic membrane as a function of the treatment temperature (input from Figure 3 and $6 a-b)$. The heating time increases exponentially upon lowering the heating temperature, in line with the statement of chemical changes. (d) Adsorption isotherms of an untreated (hydrophobic fibers; water repellant) and long-term stored at RT (hydrophilic fibers; water absorbing) silica nanofibrous membrane and a heat treated membrane at $500^{\circ} \mathrm{C}$ for $3 \mathrm{~h}$ (hydrophobic fibers; water absorbing). Even though the heat treated sample is hydrophilic, the total water uptake is the lowest due to loss of water attracting silanols.

A more intensive study of the wetting behavior of silica nanofibrous membranes was carried out using Dynamic Vapor Sorption (DVS). DVS measures how much of a solvent, in general water, is absorbed by a material by varying the vapor concentration surrounding the material. By following the material's mass at equilibrium upon a stepwise change in humidity, the water sorption isotherm is determined, which shows the equilibrium water sorption/desorption as a 


\section{WILEY-VCH}

function of the relative humidity. This in contrast to water contact angle measurements, which are momentary assessments of the water repellent or absorbing behavior.

The adsorption isotherms of the three different type of membranes, namely an untreated, longterm stored (for 5 months; RT; 65\% RH) and heat treated membrane ( $3 \mathrm{~h}$ at $500^{\circ} \mathrm{C}$ ) were recorded (Figure 6d). All 3 curves are similar in shape and correspond to a so-called Type II adsorption isotherm according to IUPAC, a characteristic form for a macroporous adsorbent. ${ }^{[52,53]}$ The total water adsorption when equilibrium was reached is the highest for the long-term stored membrane at room temperature (green line) and the lowest for the heat treated sample (red line), with an intermediate behavior for the untreated membrane (blue line). The latter membrane has hydrophobic ethyl groups at the surface of the fibers, obstructing at first sight the penetration of water in the pores, resulting in a high water contact angle. Gradually though the water is able to penetrate and at equilibrium, more water is adsorbed compared to the heat treated membrane, in which the water attracting silanols have been removed by the heat treatment. The long-term stored membrane has water attracting silanols and no water repellent ethoxy groups, explaining the highest total water uptake.

Based on all the above, a 2D schematic representation of the evolution of the silica nanofibers on the molecular level is given (Figure 7). Over time (hour to month scale), the remaining ethoxy groups, present due to incomplete hydrolysis in the production of the sol-gel system prior to electrospinning, react with moisture in the air, resulting in removal of the hydrophobic ethyl groups with the formation of silanols instead. At room temperature, this results in a switch from a highly hydrophobic membrane to a membrane with complete and immediate wetting when stored in high relative humidity environments. This chemical conversion is strongly accelerated by imposing the membrane to higher temperatures. At $400^{\circ} \mathrm{C}$ or higher, on top of this reaction, significant condensation of silanols is possible at hour scale, resulting in a higher cross-linking density of the molecular structure of the silica nanofibers. A removal of all hydrophilic groups on the surface of the fibers can finally be achieved, resulting in a silica 
nanofibrous membrane with hydrophobic nanofibers, but due to the capillary effect of the pores, the nanofibrous membrane remains water absorbing.

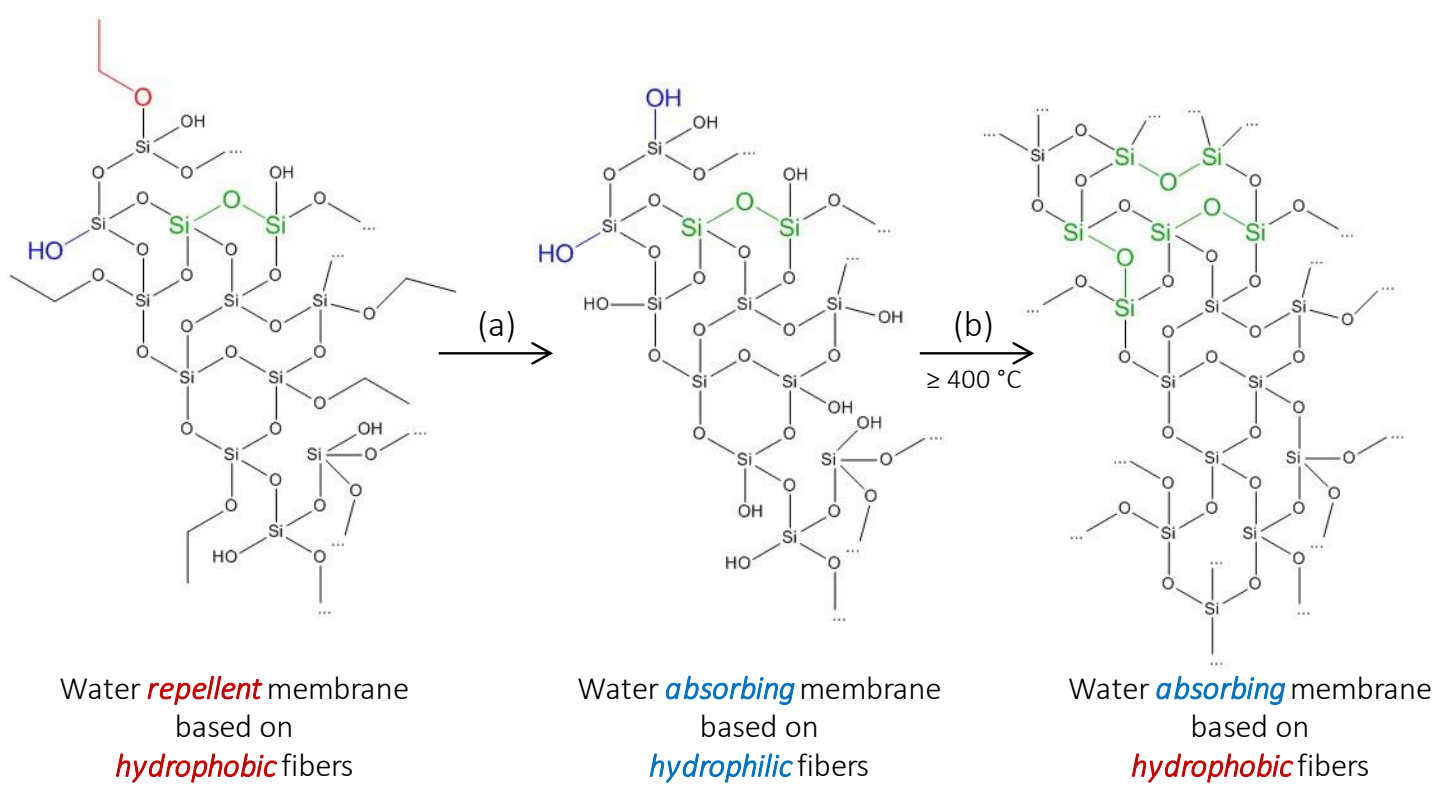

Figure 7. Chemical changes of silica nanofibers due to interaction with moisture with/without heat treatment: (a) ethoxy groups can always react with moisture in the air resulting in the formation of extra silanol groups. The ethoxy groups are permanently removed under the form of ethanol. This chemical change is accelerated at higher temperatures; (b) at $400^{\circ} \mathrm{C}$ or higher, the amount of hydroxyl bonds strongly decreases, leading to a higher cross-linking density.

\subsection{Application}

Figure 8a-f shows the gravity-driven separation of the heterogeneous azeotropic mixture toluene - water (azeotrope in case of $20.20 \mathrm{~m} \%$ water; boiling point $82^{\circ} \mathrm{C}$ ) with an untreated, water repellent and a heat treated $\left(3 \mathrm{~h}\right.$ at $\left.500^{\circ} \mathrm{C}\right)$ water absorbing silica nanofibrous membrane. If a water repellent membrane is used, toluene can pass through the porous structure, while the passage of water is prevented by the hydrophobic nature of the membrane (Figure 7, left). On the contrary, if a heat treated, thus water absorbing membrane is used (Figure 7, right), water passes through and toluene stays on top of the membrane. To confirm the purity of the obtained phases, ${ }^{1} \mathrm{H}-\mathrm{NMR}$ analyses were performed. Figure $8 \mathrm{~g}$-h show the spectra for the separation of the toluene - water mixture with a hydrophobic membrane. Based on comparison of the surface area underneath the peaks, the purity of the toluene phase is higher than 99 mol\% and only trace elements of toluene can be detected in the water phase with ${ }^{1} \mathrm{H}-\mathrm{NMR}$. Similar purities can be 


\section{WILEY-VCH}

obtained by using a heat treated membrane instead of an untreated one (Figure S6, Supporting

Information). It is important to notice that the actual purity of the toluene phase is even higher, because a comparable amount of water was found in the ${ }^{1} \mathrm{H}-\mathrm{NMR}$ of the solvent de-acetone

(Figure S7, Supporting Information).
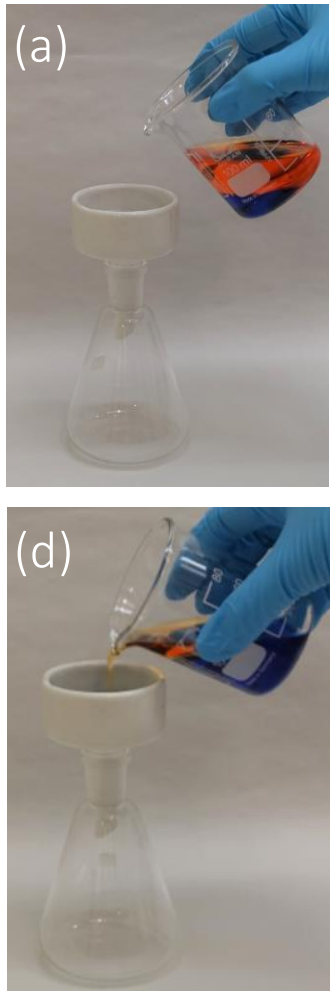
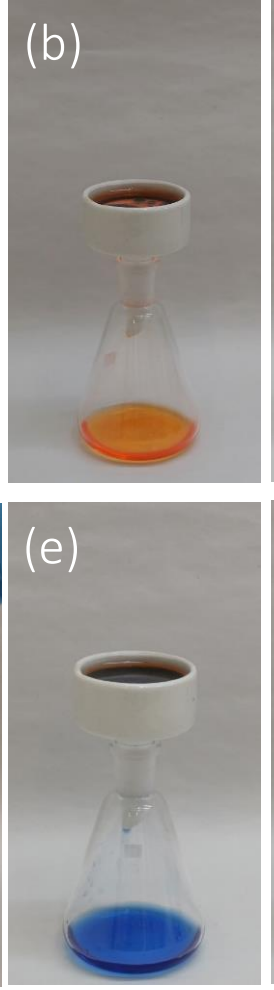
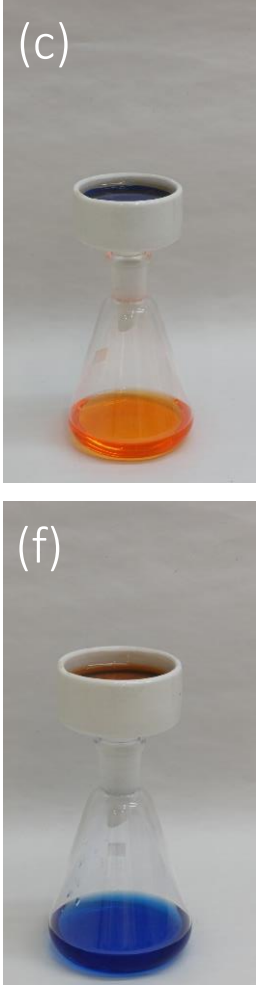

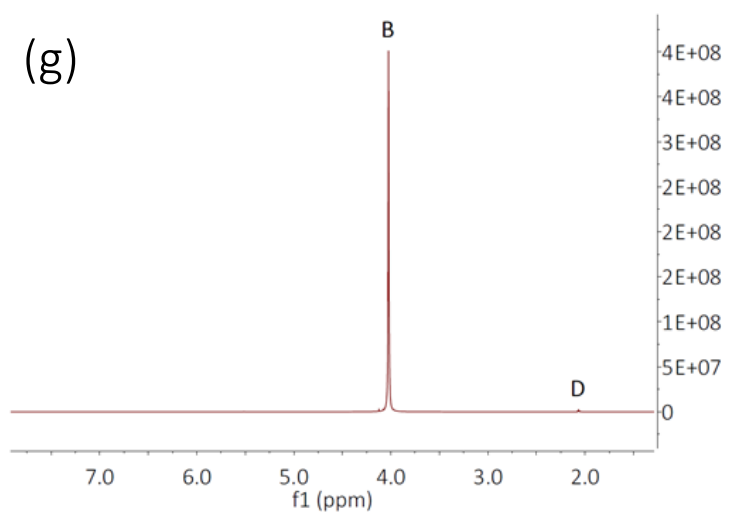

(h)

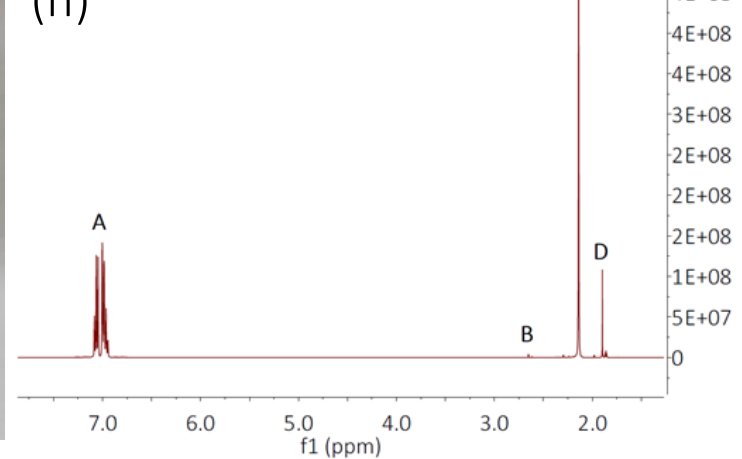

Figure 8. Separation of the binary heterogeneous azeotrope toluene-water using an untreated and a heat treated $\left(3 \mathrm{~h}\right.$ at $500^{\circ} \mathrm{C}$ ) silica nanofibrous membrane. (a-c) Blue colored water stays on top of an untreated membrane (Figure 7, left) and orange colored toluene passes through. (df) For a heat treated membrane (Figure 7, right), water passes through and toluene stays on top. ${ }^{1} \mathrm{H}-\mathrm{NMR}$ results after separation over an untreated silica nanofibrous membrane are given in $(\mathrm{g})$ for the water phase and (h) for the toluene phase. (A: $o, m, p$ toluene, B: water, C: methyl group toluene, D: de-acetone) Analogous figure for the separation with a heat treated membrane: Figure S5, Supporting Information.

To further confirm that silica nanofibrous membranes showcase a large potential for the separation of heterogeneous mixtures of liquid, the heterogeneous azeotrope methanol $-n$ hexane was tested as well, employing a heat treated membrane $\left(3 \mathrm{~h}\right.$ at $\left.500^{\circ} \mathrm{C}\right)$. In case of complete saturation of the methanol $-n$-hexane mixture, the $n$-hexane-rich phase consists of $85 \% n$-hexane and $15 \%$ methanol, and the methanol-rich phase consist of $58 \%$ methanol and $42 \% n$-hexane. After separation with the silica nanofibers, a purity above $99.5 \mathrm{~mol} \%$ for both the methanol and $n$-hexane phase were measured with ${ }^{1} \mathrm{H}-\mathrm{NMR}$ (Figure S8, Supporting 


\section{WILEY-VCH}

Information), resulting in two separated solvents. Note that the focus is placed on the physical separation of the heterogeneous azeotropic mixture into two liquids with high purity, not a complete separation on the molecular level.

Additionally, the clean water permeability of the used silica nanofibrous membranes is $26.8 \times 10^{4} \mathrm{~L} \cdot \mathrm{m}^{-2} \cdot \mathrm{h}^{-1} \cdot \mathrm{bar}^{-1}$, which is 100 times higher than commercially available microfiltration membranes and in line with other state-of-the-art investigated nanofibrous membranes, and thus enables very fast, gravity driven separation. ${ }^{[54-58]}$ This results in a pressure drop below 0.1 bar for cross-flow filtration and below 0.3 bar for dead-end filtration. ${ }^{\text {[59-61] }}$ Moreover, the silica nanofibers resist environments with a $\mathrm{pH}$ ranging from 0 to 10 for at least 24 hours. Exposure of samples in demineralized water at $35^{\circ} \mathrm{C}$ and an acidic environment of $\mathrm{pH} 4$ at RT for 10 months show no damage or fiber breakage (Figure S9, Supporting Information). Therefore, it can be stated that due to the high efficiency, simplicity, and high speed, the use of silica nanofibrous membranes as separation technique for heterogeneous mixtures is a promising alternative for energy-intensive and time consuming techniques as centrifugation, decantation or chromatography. ${ }^{[35-36,40-42]}$

\section{Conclusion}

The wetting behavior of electrospun silica nanofibrous membranes was studied, both after production over prolonged aging at various relative humidities and by imposing a heat treatment. After electrospinning the membrane is highly hydrophobic (contact angle $>140^{\circ}$ ). This hydrophobic nature can be controlled by the conditions in which it is maintained. The lower the relative humidity, the longer the hydrophobic nature is maintained. Keeping the membrane in a highly humid environment, results in superhydrophilic properties (contact angle $<5^{\circ}$ ), enabling applications that make use of both hydrophobic and hydrophilic membranes. This transition is attributed to reaction of remaining ethoxy groups, present due to incomplete hydrolysis of the TEOS precursor, with moisture in the air, resulting in an increase in hydrophilic silanol groups in the nanofibers. Acceleration of this chemical conversion can be 


\section{WILEY-VCH}

achieved by applying a heat treatment, with even complete removal of hydrophilic groups on the surface of the fibers at treatments of $400^{\circ} \mathrm{C}$ or higher. In this way, a water absorbing membrane is produced, despite the removal of the hydrophilic groups, due to the capillary effect of the macropores. Tuning of this water repellent and absorbing nature of the silica nanofibrous membranes is characteristic for the material's synthesis, namely direct electrospinning of the sol-gel system without a sacrificing organic carrier. In this way, a thermal treatment to obtain ceramic nanofibers is avoided, allowing the presence of silanol groups at the surface which can be used for further functionalization.

The above features allow tuning of the silica nanofibrous membrane towards the separation of heterogeneous azeotropes. (Super)hydrophobic or hydrophilic electrospun membranes allow separation of two immiscible phases in a single-unit operation with fast gravity driven separation. A simple, energy efficient separation technique to allow for process intensification is therefore created, replacing more intensive techniques such as centrifugation, chromatography, and decantation. The silica nanofibrous membranes are showcased to separate toluene and water with a purity higher than 99 mol\% using a hydrophobic membrane and higher than $99.9 \mathrm{~mol} \%$ using a hydrophilic membrane. The wider applicability of the silica nanofibrous membrane was further confirmed by separating methanol and $n$-hexane using a hydrophilic membrane, resulting in a purity above $99.5 \mathrm{~mol} \%$.

\section{Experimental section}

Materials: For the electrospinning process, the sol-gel precursor TEOS (reagent grade 98\%) and the catalyst $(\mathrm{HCl}, 37 \%)$ were obtained from Sigma-Aldrich and used as received. The solvent, absolute ethanol, was obtained from Fiers.

The separation of heterogeneous azeotropes was tested using toluene (>99.7\%) from Fluka, methanol (> 99.9\%) from Carl Roth and hexane (99\%, ACS reagent) from Acros organics, all used as received. For proof of concept, water has been colored using Astrazon Blue FGRL $200 \%$ from Dystar and toluene has been colored with C.I. Disperse Orange 30 . For the ${ }^{1} \mathrm{H}-\mathrm{NMR}$ 


\section{WILEY-VCH}

experiments, deuterated acetone 99.9 atom\% D was obtained from Sigma-Aldrich and used as solvent and used as received.

Electrospinning of TEOS-based nanofibers: Silica nanofibers were made using the methodology described in previous work. ${ }^{[25,26]}$ A solution of TEOS, ethanol, distilled water and $\mathrm{HCl}$ at molar ratios of 1:2:2:0.01 was used. TEOS was mixed with ethanol and an aqueous $\mathrm{HCl}$ solution was added under vigorous stirring in a second stage. After "completion" of the exothermic hydrolysis reaction, the solution was heated at $80^{\circ} \mathrm{C}$ under stirring until the volume decreased to about $3 / 8^{\text {th }}$ of the initial volume and the desired viscosity (between 120 and $200 \mathrm{mPa} . \mathrm{s}$ ) was reached. ${ }^{[25,26]}$ Prior to electrospinning the viscosities of the solutions were measured using a Brookfield viscometer LVDV-II. The electrospinning experiments were executed on a rotating drum collector using a dual moving needle set-up. The tip-to-collector distance was fixed at $15 \mathrm{~cm}$, the flow rate at $1 \mathrm{~mL} \mathrm{~h}^{-1}$ and the voltage was adjusted between 20 and $25 \mathrm{kV}$ to obtain a stable electrospinning process. All the experiments were executed at room temperature of $20^{\circ} \mathrm{C} \pm 2{ }^{\circ} \mathrm{C}$. Nanofibrous membranes with a density of $\pm 10 \mathrm{~g} \mathrm{~m}^{-2}$ were obtained. Characterization of silica nanofibrous membranes: Heat treatments were performed in Nabertherm muffle furnaces, with heating at $10^{\circ} \mathrm{C} \mathrm{min}^{-1}$ in air. All heating times indicated include the heating of the oven. The morphology and the diameters of the nanofibers were examined using a FEI Quanta $200 \mathrm{~F}$ SEM at an accelerating voltage of $20 \mathrm{kV}$. Prior to analysis the samples were coated using a sputter coater (Emitech SC7620, Au coating). Image J software was used to determine the nanofiber diameters by taking an average of 50 measurements per sample. X-ray powder diffraction (XRD) was used to determine the amorphous/crystalline nature of the silica nanofibers after various heat treatments. The analysis on precipitated nanopowders was collected on a Thermo Scientific ARL X'tra Diffractometer (CuKa, $1.5405 \AA$ A) with solid state Si-Li detector. The measurements were performed in a $\theta$-2 $\theta$ geometry over an angular range of $10-60^{\circ}$ using a $0.02^{\circ}$ step size and a $1 \mathrm{~s}$ step counting time. The recovery from creasing was tested in line with the ISO 2313:1972 standard for textile materials. 


\section{WILEY-VCH}

A sample with dimensions $1.5 \mathrm{~cm} \mathrm{x} 4 \mathrm{~cm}$ is placed in a metallic sample holder and horizontally folded over $180^{\circ}$, which is placed in a plastic sample holder on which a mass of $1 \mathrm{~kg}$ is placed for 5 minutes. After release, the sample is able to recover for 5 minutes at neutral position, after which the angle of recovery is measured. The ATR-FTIR spectra of the nanofibers were recorded on a Nicolet iS50 FT-IR set-up with OMNIC software in the range $400-4000 \mathrm{~cm}^{-1}$ with a resolution of $4 \mathrm{~cm}^{-1}$ and 32 scans for each measurement. The area between $1900-2400 \mathrm{~cm}^{-1}$ in the obtained data contains noise due to the fluctuating water vapor and $\mathrm{CO}_{2}$ in the air and was compensated for. In all cases, the reference sample is a spectra taken within 20 days after production. The cross-linking density of the silica nanofibrous membranes was measured with using ${ }^{29} \mathrm{Si}$ MAS NMR. The spectra were recorded at $74.49 \mathrm{MHz}$ on a Bruker AVANCE400 III-HD WB spectrometer. An overall 20000 free induction decays were accumulated. The excitation pulse and recycle time were $30^{\circ}$ and $10 \mathrm{~s}$, respectively. Chemical shifts were measured relative to a tetramethylsilane standard. Deconvolution of the ${ }^{29} \mathrm{Si}$ MAS NMR spectra was performed with DM2011 software. Peaks were observed centered at -91 ppm for $\mathrm{Q}^{2}$ species, -101 $\mathrm{ppm}$ for $\mathrm{Q}^{3}$ species and $-110 \mathrm{ppm}$ for $\mathrm{Q}^{4}$ species. Isothermal TGA experiments were performed on a Netzsch STA449 FR Jupiter set-up and analyzed with Netzsch Proteus software. A heat treatment with temperature increase of $10^{\circ} \mathrm{C} \cdot \mathrm{min}^{-1}$ from RT till $150,200,250,300,350,400,450$ and $500^{\circ} \mathrm{C}$ under air were performed, after which the temperature was kept constant for 3 to 60 hours. To investigate the change in hydrophilicity at room temperature, TGA-MS experiments were performed on a Netzsch STA 409 PC TGA equipment linked to a Netzsch QMS 403C, using a temperature increase of $10^{\circ} \mathrm{C} \cdot \mathrm{min}^{-1}$ from RT till $1000^{\circ} \mathrm{C}$ under helium atmosphere. The chemical resistance of the nanofibers was determined by immersing samples in $\mathrm{HCl}$ solutions of different $\mathrm{pH}$ for 24 hours.

Wettability experiments: Contact angle experiments were performed on a DSA 30 Krüss GmbH drop shape analyzer using a droplet of $2 \mu \mathrm{l}$ demineralized water. Per sample, 10 to 20 measurements were executed. DVS measurements were performed on a TA instruments Q5000 


\section{WILEY-VCH}

SA DVS device. A stepwise humidity change of 5\% was performed from $0 \%$ to $98 \%$ and reverse. Each equilibrium step was aborted if the percent mass change was smaller than 0.05 for 30 minutes and took maximum $480 \mathrm{~min}$. Prior to this stepwise change at $23^{\circ} \mathrm{C}$, a drying cure at $60^{\circ} \mathrm{C}$ was executed to a humidity of $0 \%$, step aborted if the percent mass change was smaller than 0.05 for 30 minutes and took maximum $480 \mathrm{~min}$.

Application: The separation of toluene - water and methanol - hexane was performed by pouring a mixture of the heterogeneous azeotrope on top of a hydrophobic and heat treated $\left(500^{\circ} \mathrm{C} 3 \mathrm{~h}\right)$ silica nanofibrous membrane, similar to a dead-end filtration system. Depending on the nature of the membrane, one of the phases will pass through the membrane, while the other will stay on top. Samples of each phase were taken for ${ }^{1} \mathrm{H}-\mathrm{NMR}$ analysis after waiting for 1 minute till the last droplet of liquid passed through the membrane. The purity was analyzed by ${ }^{1} \mathrm{H}-\mathrm{NMR}$. The spectra were recorded at $400 \mathrm{MHz}$ and ambient temperature with deuterated acetone as solvent, using a Bruker Avance II spectrometer equipped with a Broadband Observe (BBO) probe. For the separation of toluene and water, following peaks are observed: $\left(\mathrm{C}_{7} \mathrm{H}_{8}\right)$, $2.32 \mathrm{ppm}\left(\mathrm{s}, 3 \mathrm{H}, \mathrm{CH}_{3}\right), 7.1-7.2 \mathrm{ppm}(\mathrm{m}, 3 \mathrm{H}, \mathrm{CH}(o / p)), 7.1-7.2 \mathrm{ppm}(\mathrm{m}, 2 \mathrm{H}, \mathrm{CH}(m)) ;\left(\mathrm{H}_{2} \mathrm{O}\right)$, $2.84 \mathrm{ppm}(\mathrm{s}, 2 \mathrm{H}), 2.81$ (t, HDO). For the separation of methanol and hexane the peaks are: (nhexane, $\left.\mathrm{C}_{6} \mathrm{H}_{14}\right), 0.88$ ppm (t, $\left.6 \mathrm{H}, \mathrm{CH}_{3}\right), 1.28 \mathrm{ppm}\left(\mathrm{m}, 8 \mathrm{H}, \mathrm{CH}_{2}\right) ;(\mathrm{CH} 3 \mathrm{OH}) 3.31 \mathrm{ppm}(\mathrm{s}, 3 \mathrm{H}$, $\left.\mathrm{CH}_{3}\right), 3.12 \mathrm{ppm}(\mathrm{s}, 1 \mathrm{H}, \mathrm{OH})$. In both cases, deuterated acetone was used as solvent, corresponding to $2.09 \mathrm{ppm}\left(\mathrm{s}, 6 \mathrm{H}, \mathrm{CH}_{3}\right)$.

\section{Supporting Information}

Supporting Information is available from the Wiley Online Library or from the author.

\section{Acknowledgements}

The Research Foundation - Flanders (FWO) is gratefully acknowledged by E.L. for funding the research through a SB PhD grant (1S82918N). D.R.D. acknowledges the FWO through a postdoctoral fellowship. K.D.C. thanks BOF-UGent (BAS funding).

Received: ((will be filled in by the editorial staff))

Revised: ((will be filled in by the editorial staff)) Published online: ((will be filled in by the editorial staff)) 


\section{WILEY-VCH}

References

[1] Y. Han, Z. Xu, C. Gao, Adv. Funct. Mater. 2013, 23, 3693.

[2] Z. Xu, L. Wang, C. Yu, K. Li, Y. Tian, L. Jiang, Adv. Funct. Mater. 2018, 28, 1.

[3] L. Zhang, B. Tang, J. Wu, R. Li, P. Wang, Adv. Mater. 2015, 27, 4889.

[4] X. Wang, J. Yu, G. Sun, B. Ding, Mater. Today 2016, 19, 403.

[5] V. V. Namboodiri, R. Ponangi, L. M. Vane, Eur. Polym. J. 2006, 42, 3390.

[6] W. Zhang, N. Liu, Y. Cao, Y. Chen, L. Xu, X. Lin, L. Feng, Adv. Mater. 2015, 27, 7349.

[7] J. Zhang, S. Seeger, Adv. Funct. Mater. 2011, 21, 4699.

[8] M. Padaki, R. Surya Murali, M. S. Abdullah, N. Misdan, A. Moslehyani, M. A. Kassim, N. Hilal, A. F. Ismail, Desalination 2015, 357, 197.

[9] A. Alkhudhiri, N. Darwish, N. Hilal, Desalination 2012, 287, 2.

[10] J. J. Li, Y. N. Zhou, Z. H. Luo, Chem. Eng. J. 2017, 322, 693.

[11] M. M. Khin, a. S. Nair, V. J. Babu, R. Murugan, S. Ramakrishna, Energy Environ. Sci. 2012, 5, 8075 .

[12] J. Geltmeyer, H. Teixido, M. Meire, T. Van Acker, K. Deventer, F. Vanhaecke, S. Van Hulle, K. De Buysser, K. De Clerck, Sep. Purif. Technol. 2017, 179, 533.

[13] S. Varagnolo, F. Raccanello, M. Pierno, G. Mistura, M. Moffa, L. Persano, D. Pisignano, $R S C A d v$. 2017, 7, 5836.

[14] D. Ebert, B. Bhushan, J. Colloid Interface Sci. 2012, 384, 182.

[15] Y. Si, Q. Fu, X. Wang, J. Zhu, J. Yu, G. Sun, B. Ding, ACS Nano 2015, 9, 3791.

[16] K. M. Dobosz, C. A. Kuo-Leblanc, T. J. Martin, J. D. Schiffman, Ind. Eng. Chem. Res. 2017, 56, 5724 .

[17] M. H. Tai, J. Juay, D. D. Sun, J. O. Leckie, Sep. Purif. Technol. 2015, 156, 952.

[18] A. Raza, B. Ding, G. Zainab, M. El-Newehy, S. S. Al-Deyab, J. Yu, J. Mater. Chem. A 2014, 2, 10137. 


\section{WILEY-VCH}

[19] S. Ramakrishna, An Introduction to Electrospinning and Nanofibers; World Scientific, 2005.

[20] F. E. Ahmed, B. S. Lalia, R. Hashaikeh, Desalination 2015, 356, 15.

[21] A. Greiner, J. H. Wendorff, Angew. Chemie - Int. Ed. 2007, 46, 5670.

[22] S. Ramakrishna, K. Fujihara, W. E. Teo, T. Yong, Z. Ma, R. Ramaseshan, Mater. Today 2006, 9, 40 .

[23] S. Peng, G. Jin, L. Li, K. Li, M. Srinivasan, S. Ramakrishna, J. Chen, Chem. Soc. Rev. 2016, 45,1225 .

[24] J. J. Li, Y. N. Zhou, Z. H. Luo, ACS Appl. Mater. Interfaces 2015, 7, 19643.

[25] J. Geltmeyer, L. Van Der Schueren, F. Goethals, K. De Buysser, K. De Clerck, J. SolGel Sci. Technol. 2013, 67, 188.

[26] J. Geltmeyer, J. De Roo, F. Van den Broeck, J. C. Martins, K. De Buysser, K. De Clerck, J. Sol-Gel Sci. Technol. 2016, 77, 453.

[27] S. Agarwal, A. Greiner, J. H. Wendorff, Prog. Polym. Sci. 2013, 38, 963.

[28] A. Baji, Y. Mai, In Polymer-Engineered Nanostructures for Advanced Energy Applications; 2017.

[29] M. Guo, B. Ding, X. Li, X. Wang, J. Yu, M. Wang, J. Phys. Chem. C 2010, 114, 916.

[30] S.-S. Choi, S. G. Lee, S. S. Im, S. H. Kim, Y. L. Joo, J. Mater. Sci. Lett. 2003, $22,891$.

[31] C. J. Brinker, G. W. Scherer, Sol-Gel Science: The Physics and Chemistry of Sol-Gel Processing; Elsevier Science, 1990.

[32] G. Dubois, W. Volksen, T. Magbitang, R. D. Miller, D. M. Gage, R. H. Dauskardt, Adv. Mater. 2007, 19, 3989.

[33] Y. Dai, W. Liu, E. Formo, Y. Sun, Y. Xia, Polym. Adv. Technol. 2011, 22, 326.

[34] D. Li, J. T. McCann, Y. Xia, M. Marquez, J. Am. Ceram. Soc. 2006, 89, 1861.

[35] J. F. Richardson, J. H. Harker, J. R. Backhurst, Coulson and Richardson's Chemical Engineering; 2002; Vol. 2. 


\section{WILEY-VCH}

[36] A. Eggert, S. Sibirtsev, D. Menne, A. Jupke, Chem. Eng. Res. Des. 2017, 127, 170.

[37] J. A. Lauterbach, K. Sungtak, E. Sasmaz, M. Mayeda (Columbia SC), US 2015/0210944, 2015.

[38] J. J. Li, L. T. Zhu, Z. H. Luo, Chem. Eng. J. 2016, 287, 474.

[39] F. Chen, Y. Lu, X. Liu, J. Song, G. He, M. K. Tiwari, C. J. Carmalt, I. P. Parkin, Adv. Funct. Mater. 2017, 27.

[40] L. Li, Z. Liu, Q. Zhang, C. Meng, T. Zhang, J. Zhai, J. Mater. Chem. A 2015, 3, 1279.

[41] P. Lutze, A. Gorak, Chem. Eng. Res. Des. 2013, 91, 1978.

[42] E. Drioli, E. F. Giorno, Lidietta, Comprehensive Membrane Science and Engineering 2nd Edition; Elsevier, 2017.

[43] A. K. Pabby, S. S. H. Rizvi, A. M. S. Requena, Handbook of Membrane Separations: Chemical, Pharmaceutical, Food, and Biotechnological Applications, Second Edition; CRC Press, 2015.

[44] J. Geltmeyer, G. Vancoillie, I. Steyaert, B. Breyne, G. Cousins, K. Lava, R. Hoogenboom, K. De Buysser, K. De Clerck, Adv. Funct. Mater. 2016, 26, 5987.

[45] C. Wang, T. Yao, J. Wu, C. Ma, Z. Fan, Z. Wang, Y. Cheng, Q. Lin, B. Yang, ACS Appl. Mater. Interfaces 2009, 1, 2613.

[46] L. T. Zhuravlev, Colloids Surfaces A Physicochem. Eng. Asp. 2000, 173, 1.

[47] L. Peng, W. Qisui, L. Xi, Z. Chaocan, Colloids Surfaces A Physicochem. Eng. Asp. 2009, 334, 112.

[48] U. Stachewicz, R. J. Bailey, H. Zhang, C. a. Stone, C. R. Willis, A. H. Barber, ACS Appl. Mater. Interfaces 2015, 7, 16645.

[49] M. Ma, M. Gupta, Z. Li, L. Zhai, K. K. Gleason, R. E. Cohen, M. F. Rubner, G. C. Rutledge, Adv. Mater. 2007, 19, 255.

[50] U. Stachewicz, A. H. Barber, Langmuir 2011, 27, 3024.

[51] P. B. Sarawade, J. K. Kim, A. Hilonga, D. V. Quang, S. J. Jeon, H. T. Kim, J. Non. 


\section{WILEY-VCH}

Cryst. Solids 2011, 357, 2156.

[52] Z. A. Alothman, Materials (Basel). 2012, 5, 2874.

[53] M. Thommes, K. Kaneko, A. V. Neimark, J. P. Olivier, F. Rodriguez-Reinoso, J.

Rouquerol, K. S. W. Sing, Pure Appl. Chem. 2015, 87, 1051.

[54] D. Bjorge, N. Daels, S. De Vrieze, P. Dejans, T. Van Camp, W. Audenaert, J. Hogie, P. Westbroek, K. De Clerck, S. W. H. Van Hulle, Desalination 2009, 249, 942.

[55] J.-H. Choi, H. Y. Ng, Chemosphere 2008, 71, 853.

[56] N. L. Le, S. P. Nunes, Sustain. Mater. Technol. 2016, 7, 1.

[57] L. A. Goetz, N. Naseri, S. S. Nair, Z. Karim, A. P. Mathew, Cellulose 2018, 25, 3011.

[58] L. Huang, J. T. Arena, J. R. McCutcheon, J. Memb. Sci. 2016, 499, 352.

[59] R. H. Davis, D. C. Grant, In Membrane Handbook; Ho, W. S. W.; Sirkar, K. K., Eds.; Springer US: Boston, MA, 1992; pp. 461-479.

[60] Z. Wang, D. Liu, W. Wu, M. Liu, Desalination 2006, 201, 175.

[61] M. Zhang, L. Song, Environ. Sci. Technol. 2000, 34, 3767. 


\section{WILEY-VCH}

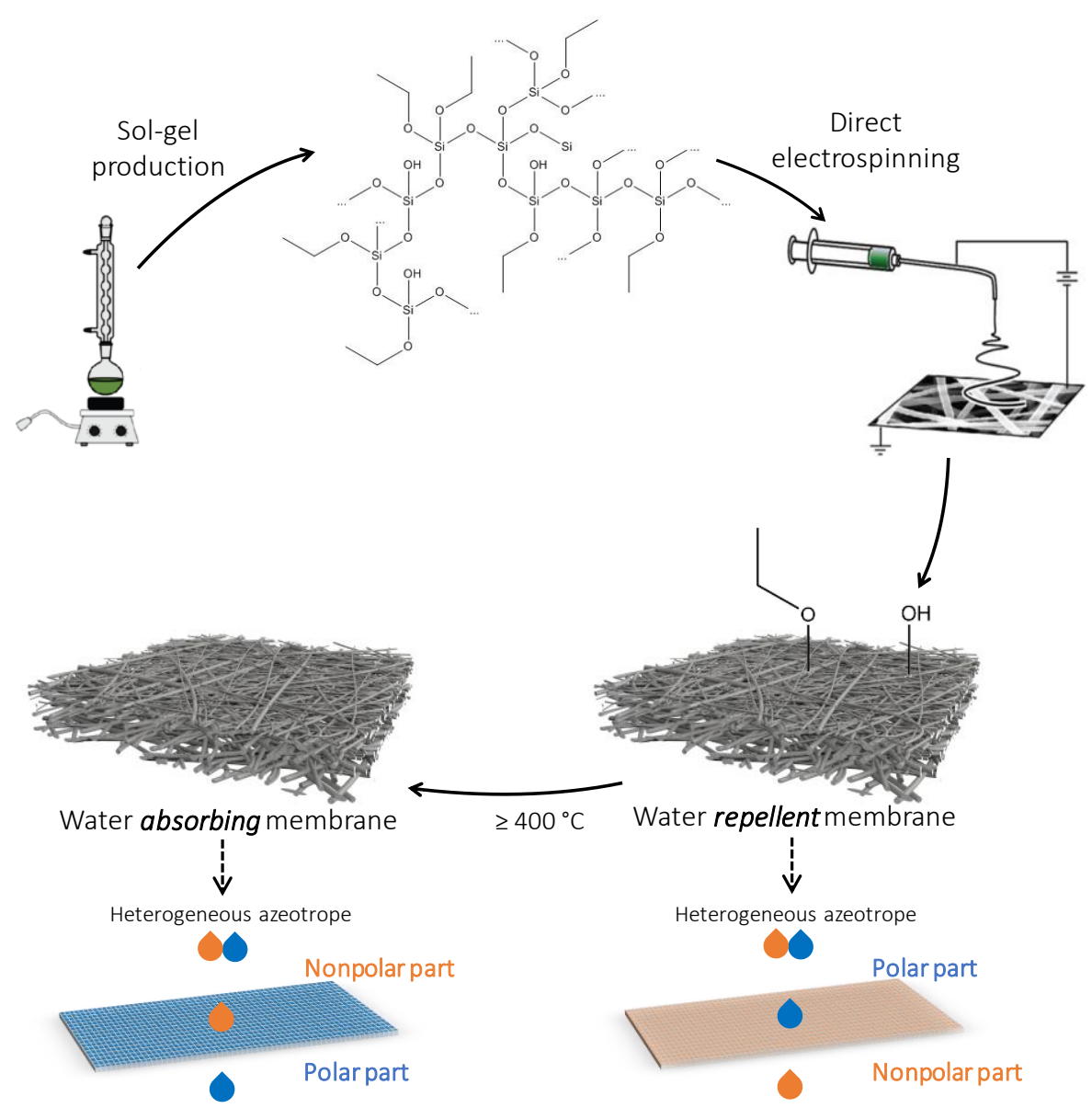

Figure 1. Silica nanofibers produced via direct electrospinning of a TEOS-based sol-gel solution create a water repellent membrane. An efficient switch to a water absorbing membrane is achieved by a heat treatment at $400^{\circ} \mathrm{C}$ or higher. In this way, gravity driven separation of heterogeneous azeotropes can be achieved via two routes.

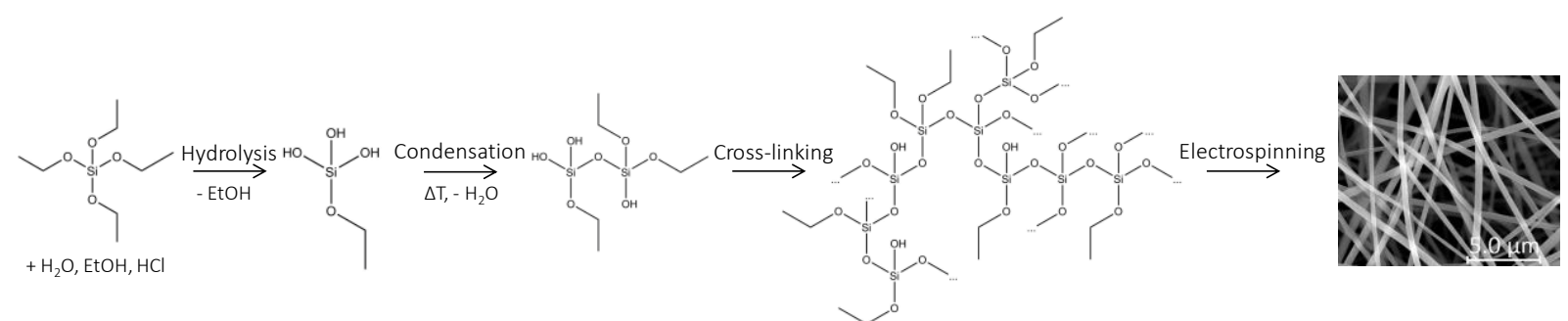

Figure 2. Principle of the production of silica nanofibrous membranes via electrospinning. Due to hydrolysis and condensation of a mixture containing TEOS, ethanol (EtOH), water, and $\mathrm{HCl}$ (molar ratios 1:2:2:0.01), a loosely cross-linked 3D electrospinnable network is obtained. 


\section{WILEY-VCH}

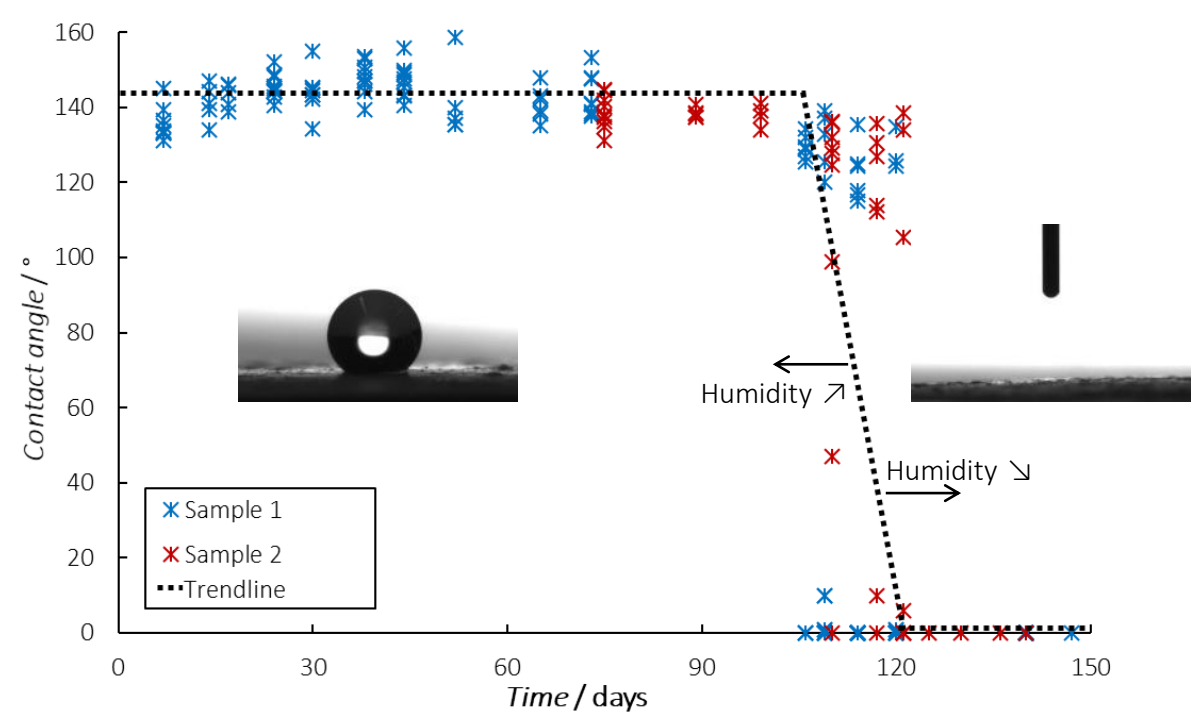

Figure 3. Evolution of the water contact angle of two silica nanofibrous membranes over time at $20^{\circ} \mathrm{C}$ and $65 \% \mathrm{RH}$. The contact angle is stable for over ca. 100 days, resulting in a hydrophobic, almost superhydrophobic $\left(>150^{\circ}{ }^{[42]}\right)$ structure. After ca. 100 days, there is a switch to a superhydrophilic $\left(<5^{\circ}\right)$ membrane, which can be explained by further hydrolysis combined with the capillary effect of the nanofibrous porous structure (cf. discussion of Figure 4, 5 and 7). This transition can be accelerated by increasing $\mathrm{RH}$, or delayed by lowering the $\mathrm{RH}^{\left[{ }^{[41]}\right.}$
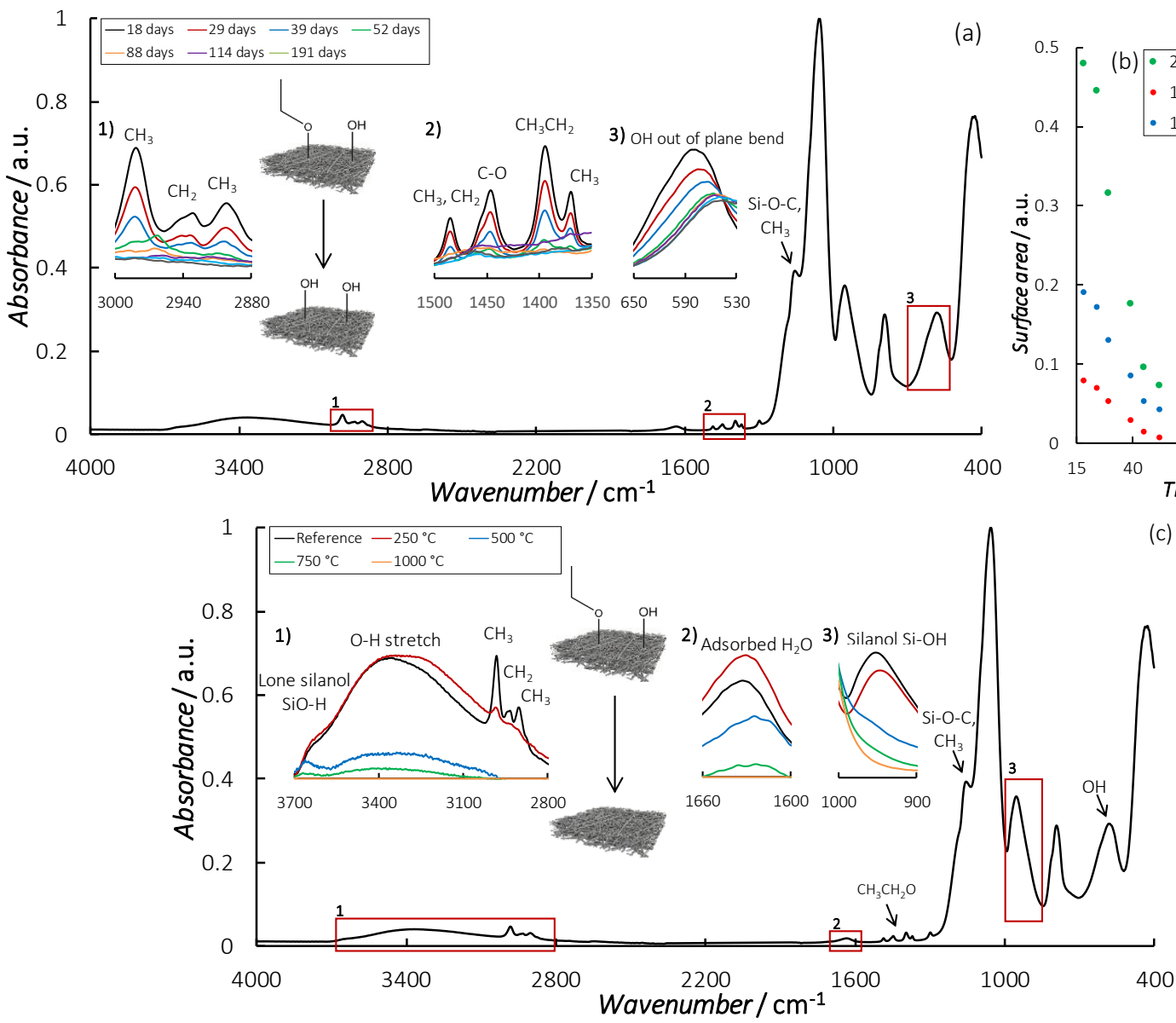

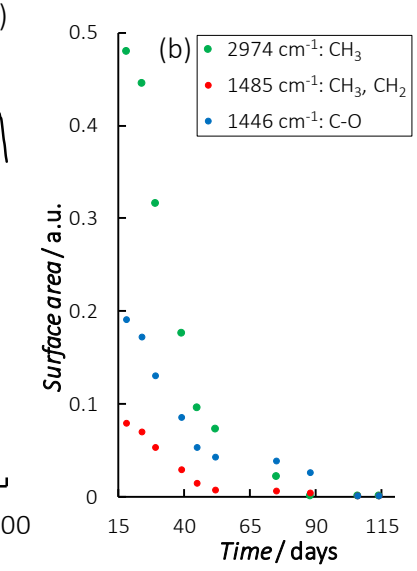

(c) 


\section{WILEY-VCH}

fibrous structure after electrospinning (Figure 2, right). Over time, these groups are gradually converted in polar groups. (b) Evolution of surface area underneath characteristic peaks of the normalized ATR-FTIR spectra over time (complete overview Table S2, Supporting Information). The surface areas gradually decrease until no peaks related to $-\mathrm{OCH}_{2} \mathrm{CH}_{3}$ vibrations and stretches are observed. (c) ATR-FTIR spectra of silica nanofibers after various heat treatments for $3 \mathrm{~h}$. These spectra indicate a gradual change in chemical nature due to reaction of remaining ethoxy and silanols accelerated at a higher treatment temperature. Peaks marked with an arrow show a similar trend.

The spectra of all samples were normalized based on the height of the largest peak, i.e. the peak at $1076 \mathrm{~cm}^{-1}$ attributed to Si-O-Si vibrations.
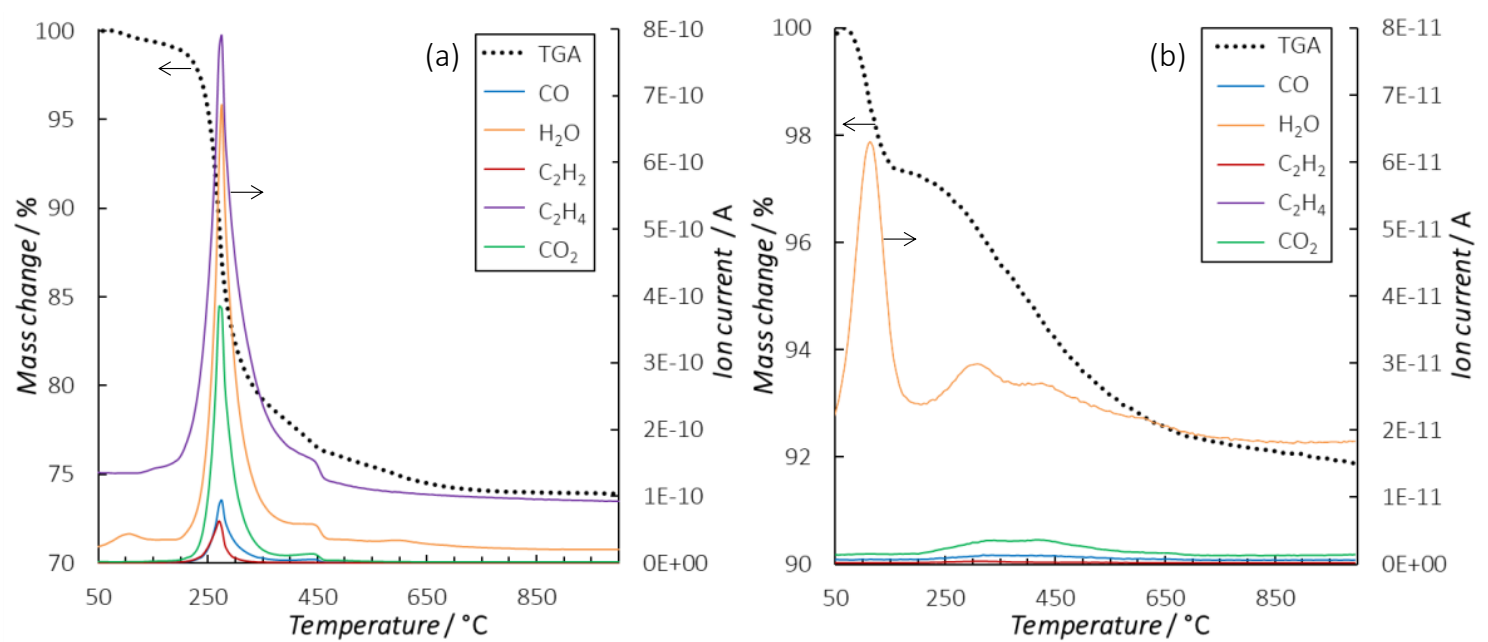

Figure 5. TGA-MS results of silica nanofibers (a) just after electrospinning (hydrophobic; left region of Figure 3) and (b) after 5 months at room temperature and 65\% $\mathrm{RH}$ (superhydrophilic; right region of Figure 3). (a) shows significant release of $\mathrm{C}_{2} \mathrm{H}_{4}, \mathrm{H}_{2} \mathrm{O}, \mathrm{CO}_{2}$, $\mathrm{CO}$ and $\mathrm{C}_{2} \mathrm{H}_{2}$ if heated at $10^{\circ} \mathrm{C} / \mathrm{min}$ up to $1000^{\circ} \mathrm{C}$ under helium atmosphere; in (b), only significant peaks of $\mathrm{H}_{2} \mathrm{O}$ and $\mathrm{CO}_{2}$ are detected. Ethoxy groups present after electrospinning eventually react with moisture in the air, resulting in a permanent transition to a superhydrophilic structure; dotted lines: TGA, colored lines: ion currents measured with MS. 


\section{WILEY-VCH}
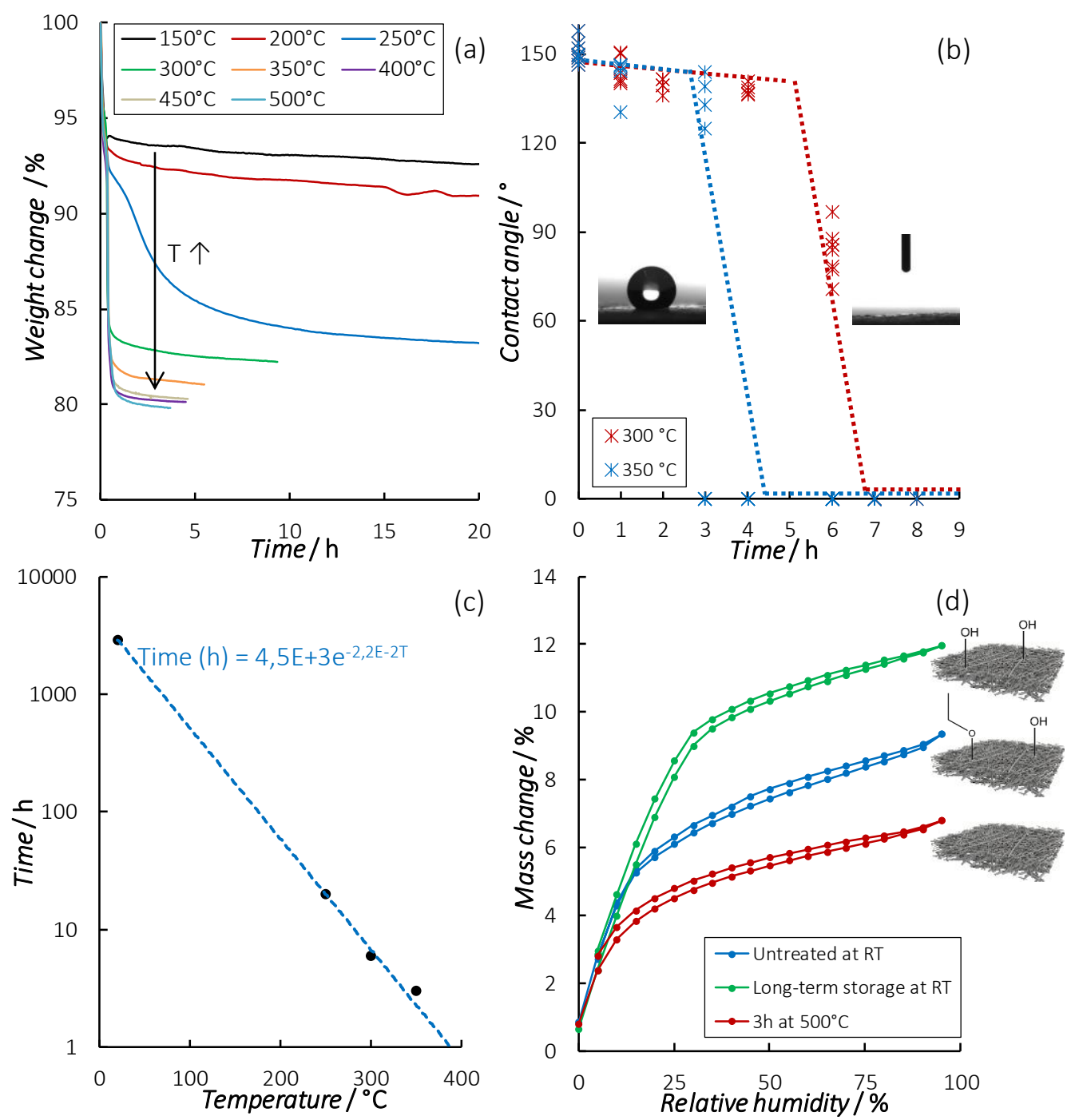

Figure 6. (a) Isothermal TGA measurements of silica nanofibers show a stronger and faster mass loss at higher temperatures. (b) Evolution of the water contact angle upon applying a heat treatment at 300 and $350^{\circ} \mathrm{C}$ for varying time (hour scale), indicating that the membrane switches to a superhydrophilic membrane. (c) Evolution of the heating time required for obtaining a superhydrophilic membrane as a function of the treatment temperature (input from Figure 3 and $6 a-b)$. The heating time increases exponentially upon lowering the heating temperature, in line with the statement of chemical changes. (d) Adsorption isotherms of an untreated (hydrophobic fibers; water repellant) and long-term stored at RT (hydrophilic fibers; water absorbing) silica nanofibrous membrane and a heat treated membrane at $500^{\circ} \mathrm{C}$ for $3 \mathrm{~h}$ (hydrophobic fibers; water absorbing). Even though the heat treated sample is hydrophilic, the total water uptake is the lowest due to loss of water attracting silanols. 


\section{WILEY-VCH}

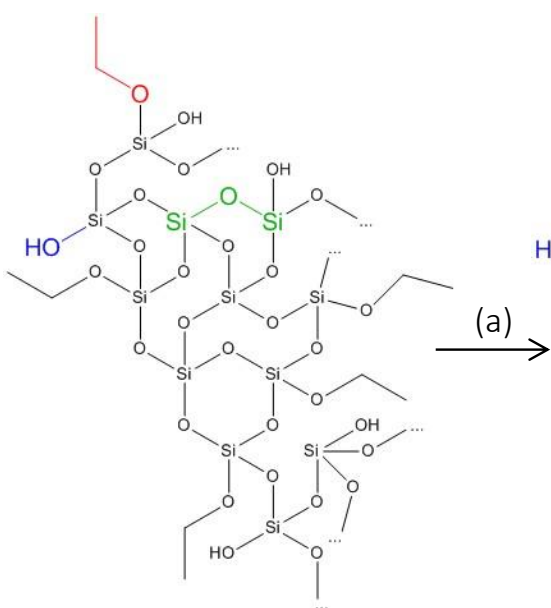

Water repellent membrane based on hydrophobic fibers

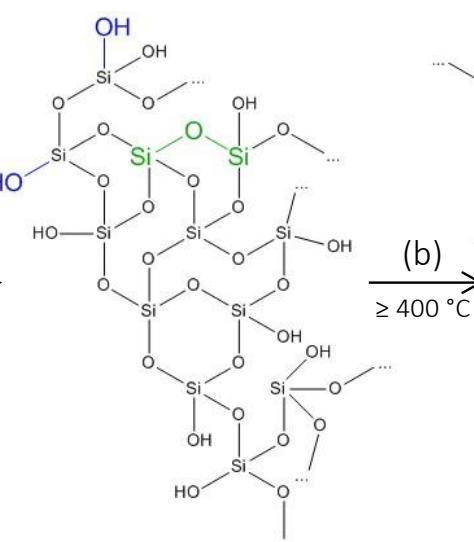

Water absorbing membrane based on hydrophilic fibers

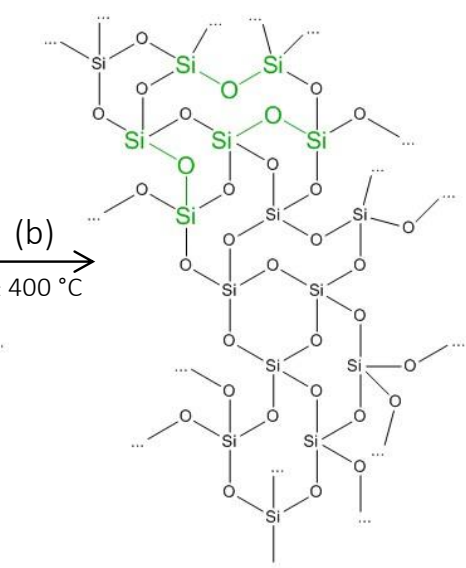

Water absorbing membrane based on

hydrophobic fibers

Figure 7. Chemical changes of silica nanofibers due to interaction with moisture with/without heat treatment: (a) ethoxy groups can always react with moisture in the air resulting in the formation of extra silanol groups. The ethoxy groups are permanently removed under the form of ethanol. This chemical change is accelerated at higher temperatures; (b) at $400^{\circ} \mathrm{C}$ or higher, the amount of hydroxyl bonds strongly decreases, leading to a higher cross-linking density.
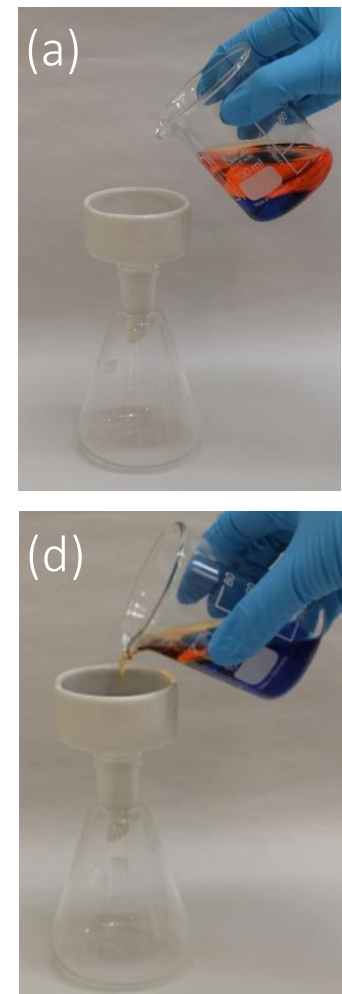
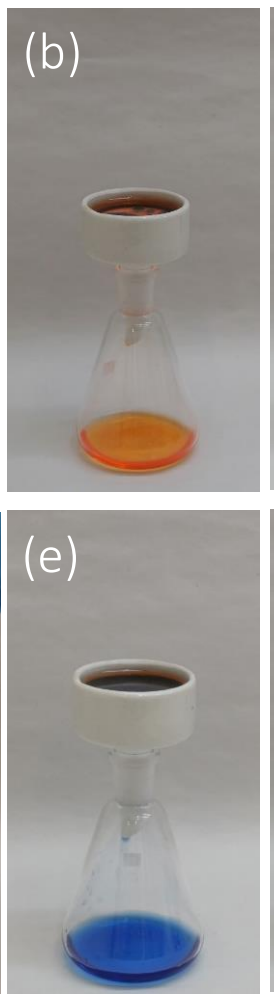
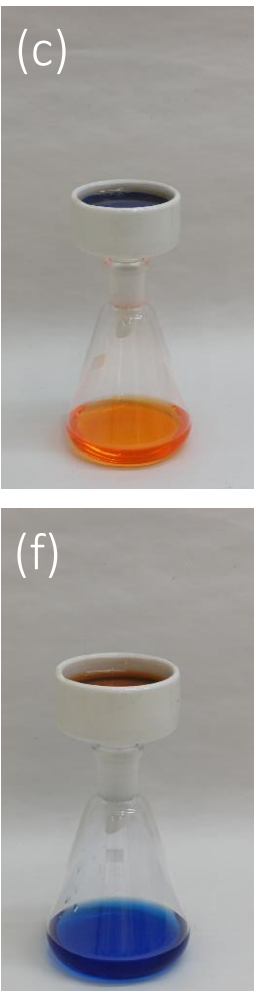

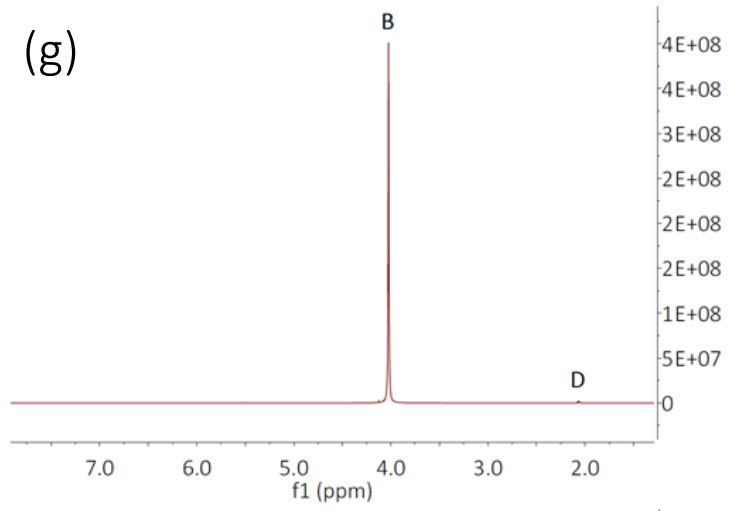

(h)

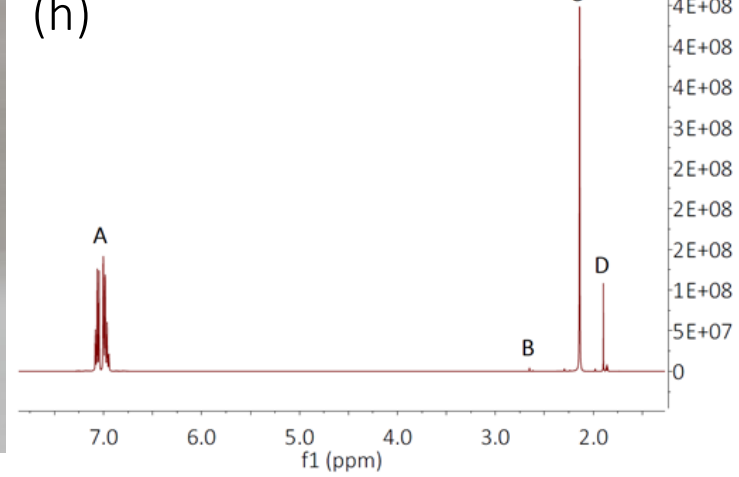

Figure 8. Separation of the binary heterogeneous azeotrope toluene-water using an untreated and a heat treated $\left(3 \mathrm{~h}\right.$ at $\left.500^{\circ} \mathrm{C}\right)$ silica nanofibrous membrane. (a-c) Blue colored water stays on top of an untreated membrane (Figure 7, left) and orange colored toluene passes through. (d-f) For a heat treated membrane (Figure 7, right), water passes through and toluene stays on top. ${ }^{1} \mathrm{H}-\mathrm{NMR}$ results after separation over an untreated silica nanofibrous membrane are given in $(\mathrm{g})$ for the water phase and $(\mathrm{h})$ for the toluene phase. (A: $o, m, p$ toluene, B: water, C: methyl 


\section{WILEY-VCH}

group toluene, D: de-acetone) Analogous figure for the separation with a heat treated membrane: Figure S5, Supporting Information. 